\title{
LEADERSHIP, PUBLIC HEALTH MESSAGING, AND CONTAINMENT OF MOBILITY \\ IN MEXICO DURING THE COVID-19 PANDEMIC
}

\author{
Sandra Aguilar-Gomez \\ Eva O. Arceo-Gomez \\ Elia De la Cruz Toledo \\ Pedro J. Torres López
}

\section{LATIN AMERICAN AND THE CARIBBEAN ECONOMIC ASSOCIATION}

February 2021

The views expressed herein are those of the authors and do not necessarily reflect the views of the Latin American and the Caribbean Economic Association. Research published in this series may include views on policy, but LACEA takes no institutional policy positions.

LACEA working papers are circulated for discussion and comment purposes. Citation of such a paper should account for its provisional character. A revised version may be available directly from the author.

(C) 2021 by Sandra Aguilar-Gomez, Eva O. Arceo-Gomez, Elia De la Cruz Toledo y Pedro J. Torres López. All rights reserved. Short sections of text, not to exceed two paragraphs, may be quoted without explicit permission provided that full credit, including (C) notice, is given to the source. 
LACEA WORKING PAPER SERIES No. 0054 February 2021

Leadership, public health messaging, and containment of mobility in Mexico during the COVID-19 pandemic

Sandra Aguilar-Gomez

Columbia University, School of International and Public Affairs

sandra.aguilar@columbia.edu

Eva O. Arceo-Gomez

Universidad Iberoamericana, Department of Economics

eva.arceo@ibero.mx

Elia De la Cruz Toledo

Loyola Marymount University, Psychology Applied Research Center

elia.delacruztoledohe@1mu.edu

Pedro J. Torres López

Universidad Iberoamericana, Department of Economics

pedroj.tol@gmail.com

\section{ABSTRACT}

The effectiveness of wide-spread policy measures in the midst of the COVID-19 pandemic hinges upon compliance with the ordinances. This study explores how leaders' discourse relates to compliance with stay-at-home orders to mitigate the spread of the COVID-19 pandemic in Mexico. We use municipality-level mobility data from geolocation events of smartphone users and daily briefings from the President and Health. Minister Dr. Hugo López-Gatell. Using quantile regressions, sentiment analysis and topic modelling, we shed light on the dynamics between political discourse and containment of mobility. We find discrepancies between the content and tone of the President and those of the COVID-19 czar. These contrasts translate into differences on the association between the content of the speeches and mobility patterns. Our findings, using a LASSO penalized quantile regression, indicate that when President AMLO's discourse is positive, mobility tends to decrease, but when the Health Minister's discourse is positive, mobility tends to increase. Across the distribution of mobility changes, those in the inter-quantile range are more responsive to the discourse. We also find that the discourse's association to mobility is mediated by awareness of COVID-related topics and by individuals' political affiliation. Lastly, we show that mobility patterns prior to the conferences are not causing a change in discourse which clears concerns over reverse causality. Overall, messaging across top officials shows mixed results on mobility, but even minor changes in mobility represent relevant channels of transmission in a pandemic. It remains untested whether a concerted message would effectively increase compliance with social distancing.

JEL Classification: D83, D91, H11, H12, I12, I18, O54.

Keywords: COVID-19, pandemic, public health messaging, geographical mobility, nonpharmaceutical prevention measures, compliance, Mexico. 


\section{ACKNOWLEDGEMENTS AND FINANCIAL DISCLOSURE}

We are grateful for the UNDP-GRANDATA and feedback provided by The Regional Bureau for Latin America and the Caribbean, United Nations Development Programme. The first version of this paper was submitted for peer review to the United Nations Development Programme Policy Response Team on November 13, 2020. All errors remain our own. 


\section{Introduction}

Leadership and prevention efforts are at the core of public health policies. Many of these efforts entail messaging to the population to take preventive measures. Effective messaging that encourages the public to protect themselves is particularly important for at-risk populations. Air quality warnings, sexual education campaigns, and obesity prevention campaigns are notable examples included in the essential toolbox of health policymakers ${ }^{1}$. The COVID-19 global pandemic is no exception: even at the eve of massive vaccination campaigns to inoculate the population, flattening the curve through enforcing or recommending social distancing or physical distancing remains to be a crucial strategy of nearly every public health agency in the world. ${ }^{2}$ The effectiveness of prevention messaging depends on consistency, reinforcement, and health authorities' leadership throughout the pandemic (Fraser, 2020; Guest et al., 2020).

People facing the need to assess the risks of engaging in outside home activities tend to rely on public authorities for guidance, as research has shown that regular people are not good at evaluating risks in their everyday life (Tversky and Kahneman, 1974). Furthermore, when the population receives mixed messages regarding a potential health risk, they may update their prior beliefs in a sub-optimal way. In the face of the global COVID-19 pandemic, leadership is crucial in handling a global health crisis. One of its key components is the success in managing populations' behavior and expectations (Michie et al., 2020). Several countries have struggled generating confidence in leadership, with health ministers in an array of countries from Czech Republic to New Zealand resigning, and some others, including Brazil and the U.S., have openly contradicted their Presidents. In Mexico, the information flow regarding the health measures to be taken has been criticized for containing

\footnotetext{
${ }^{1}$ On the impact of air pollution warnings, see, for instance Aguilar-Gomez (2020), and Neidell (2010). Kirby et al. (2007) provides an excellent review of the literature on the impact of sexual education on adolescents and youth. Finally, Kite et al. (2018) reviews the literature on the effect of obesity campaigns.

${ }^{2}$ As of January 2021 vaccination campaigns have started in most of the developed world. In Mexico a slow roll out has also started
} 
inconsistencies and contradictory messages, and for lacking credibility. ${ }^{3}$

In this paper, we seek to explore whether leaders' stance on the pandemic and their discourse on public health efforts are effectively mitigating mobility outside of people's homes and social interactions. We measure effectiveness by looking at changes in people's behavior (proxied by mobility), the number of COVID-19 cases, and COVID-19 related deaths. To get a measure of leaders' messaging, we compiled the transcriptions of daily press conferences by the Mexican President Andrés Manuel Lopez Obrador (AMLO) and his COVID-19 czar, Dr. Hugo López-Gatell (HLG). Via topic modelling, we explore whether changes in their pandemic discourse are related to mobility of the Mexican population during the COVID-19 pandemic, focusing on the period between March and September, 2020. We find that changes in tone and content in the messaging on the spread and prevalence of COVID-19 have had significant effects on population mobility, which is crucial for the containment of the outbreak and the prevention of COVID-related deaths.

In addition, we explore the the association between discourse and public awareness (proxied by exposure to the conferences using Google searches). We find that when more people watch the President's daily conference, the word "Pandemic" has a higher number of searches. In comparison, the same happens when more people watch HLG's conference and the word "Epidemic". Searches for terms like Vaccine, Test, Safe Distance, Stay Home, and COVID-related words have a positive and significant association with views of the HLG's conference. Finally, we test whether Google Searches also respond to new daily global COVID-19 cases and political affiliation. Since global cases and political affiliation are orthogonal to mobility, these variable may work well as instrumental variables. Our test revealed that lagged mobility changes do not impact the discourse of neither AMLO nor HLG and we conclude that Google Searches are exogenous.

Our work explores how political discourse is associated to population compliance of health policy recommendations in Mexico. The first strand of literature that our

\footnotetext{
${ }^{3}$ Julio Frenk, former Health Minister, criticized the communications strategy in June, 2020. Even WHO authorities have called for a coherent and consistent message.
} 
study contributes to is the work on public health messaging. Previous research has found that news about COVID-19 has an impact on the public's interest, but that this response can be very short-lived, which raises doubts on the potential effectiveness of government messaging (Bento et al., 2020). However, it has been documented that public health communication can raise awareness of infectious diseases and promote the adoption of recommended treatment regimens (Guttman and Salmon, 2004). Research in psychology and political science has highlighted the importance of delivering consistent messages to the public (Guttman and Salmon, 2004). Information is an important mechanism to change individuals' health behavior (Bursztyn et al., 2020), and citizens are highly susceptible to framing effects in their health choices (Gallagher and Updegraff, 2012). Deslatte (2020) shows that the type of messenger, that is, the President or other high-ranking officials, can shape the effectiveness of public messaging during emergency conditions, but the message alone matters. In our study we find that the two main actors within the government have diverging messages, affecting the effectiveness on mobility reduction.

Our paper will also contribute to the literature on how partisanship can shape the public's compliance with public health policies. Around the world, public messaging during the COVID-19 pandemic has diverged sharply along partisan lines. For instance, in the U.S., Republican governors have downplayed the severity of the crisis, while democratic governors have emphasized the immediate and long term consequences of the pandemic (Allcott et al., 2020) Fancourt et al. (2020) documented how the violation of lockdown rules by Dominic Cummings in England, senior aide to Boris Johnson, led to a drop in the public's confidence in the government's ability to handle the pandemic. Matters can go beyond the public's trust. Political partisanship shapes health policy directly (Green et al., 2020). In the U.S., there is evidence that partisanship has a large effect on U.S. Governors' policy responses during the pandemic (Adolph et al., 2020; Hatem and Young, n.d.). Apart from shaping policy, partisanship and discourses also have an incidence on the public's compliance with health policy recommendations. ${ }^{4}$ The most related study on this

\footnotetext{
${ }^{4}$ In the case of Italy, see Barbieri \& Bonini 2020; and for the U.S., see Allcott et al. 2020;
} 
topic with our findings is Allcott et al. (2020), who show that partisanship is a strong driver of social distancing in the U.S. However, this paper, as well as most research on partisanship and COVID 19, is based on a developed country.

Finally, this paper also contributes to the COVID-specific literature on public policy responses. All countries face the same threat but government responses vary. Many governments worldwide have implemented mandatory stay-at-home orders, punishing non-compliance with sanctions that range from a 374 Euro fine in France to revoking work passes and stripping people off their permanent-resident status in Singapore and Hong Kong. Other governments have mostly relied on public health recommendations not enforceable by law. In the case of Mexico, no punitive measures have been established for individuals, and compliance and oversight have focused on firms, which are subject to fines and closures if they do not comply with the restrictions imposed by the color-coded "COVID-19 traffic lights" system. Mexico is not alone strategy; other countries in the Latin American and Caribbean regions are also avoiding imposing sanctions on individuals. In the face of a pandemic - and the accompanying preventive measures- that seems bound to last in the medium run, permanent sanctions seem like an increasingly unlikely solution. Hence the Mexican experience emphasizing public health messaging over mandatory restrictions can shed light on whether this could be an alternative for more countries in the medium run, specially as global mobility and habitats' degradation could bring pandemic emergencies more frequently.

Mexico's political and social landscape differs from that in other regions recently explored in the literature. Still, it is extremely relevant for other developing countries that have similar conditions but worse data quality. In Mexico, there is a large informal job sector, workers lack safety nets, and there is a prevalence of housing overcrowding challenging the compliance with stay-at-home orders. On the other hand, the government has not provided economic stimuli to individuals and has merely launched a program of credits for a few firms. Hence, lessons for Mexico can be helpful for places where stay-at-home-checks are economically or politically infeasible.

Barrios \& Hochberg 2020; Grossman et al. 2020; and MacMillan 2020 
Our study sheds light on the importance of a unified public health messaging around non-mandatory health measures. When top officials repeatedly contradict each other, non-enforceable recommendations are less effective on reducing mobility and hence do not halt the spread of a pandemic.

The rest of the paper is organized as follows. Section 1 sets the paper into the Mexican context. Section 2 presents the different data sources and processing methods. Section 3 explains the empirical models. Section 4 shows our results,

whereas Section 5 explores plausible mechanisms for our findings and a test for reverse causality. Section 6 concludes.

\section{Background: The Pandemic in Mexico, Policy Re- sponse, Discourse and Context}

The COVID-19 pandemic, caused by the transmission of severe acute respiratory syndrome coronavirus 2 (SARS-CoV-2), was first identified in Mexico on February 28th. Figure 1 shows the evolution of lab-confirmed COVID-19 cases using data from the General Directorate of Epidemiology from January to September 2020. Within that period, Mexico reached the peak number of cases in late July, though, data up to February, 2021, indicates that we reached a new peak in late January. 
Figure 1: Daily confirmed COVID-19 cases

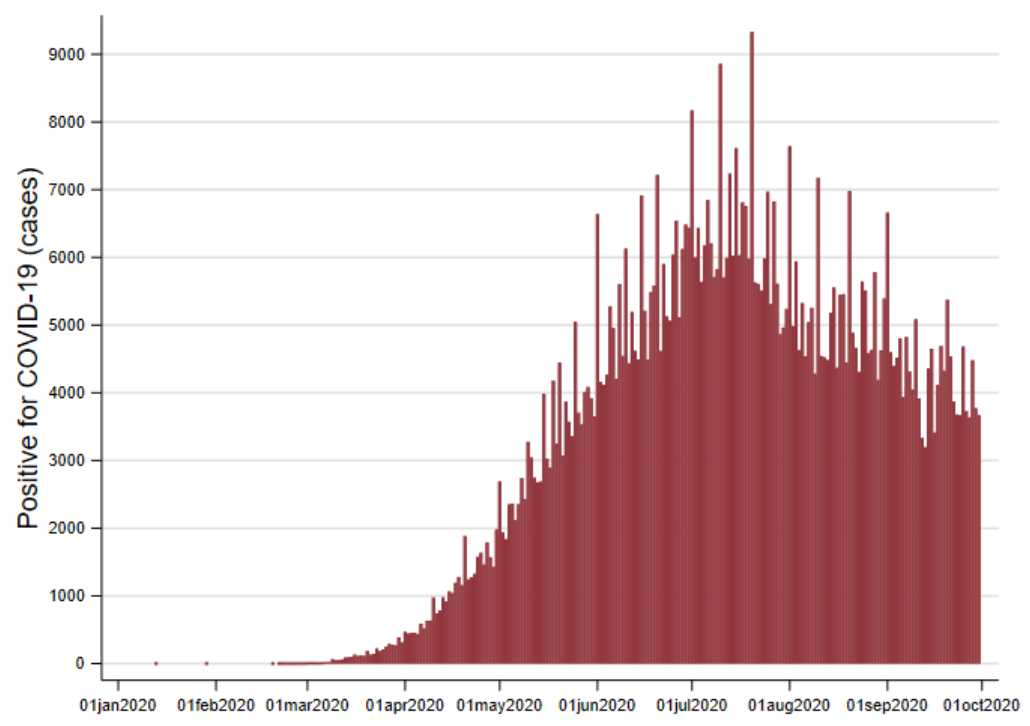

Note: Authors' estimates using data from the General Directorate of Epidemiology from January to September, 2020. The Figure shows daily confirmed COVID-19 cases. A case is considered confirmed when it has tested positive in a lab test.

There are several indicators that reveal the severity of the pandemic in Mexico. First, an indicator that has been crucial throughout the pandemic is the positivity rate of COVID-19 tests. Since April, 2020, Mexico has consistently been at the bottom of testing per 100,000 people and among the highest globally on the positivity rate. ${ }^{5}$ and $\mathrm{A} .1$ in the Appendix. At the first peak of the pandemic, positivity rates surpassed 50\% (see Figure A.1). Second, the COVID-19 outbreak has been particularly deadly in Mexico. As Figure 2 displays the death counts from confirmed COVID-19 cases. At its July 2020 peak, Mexico reached over 700 daily deaths (see Panel (a) in the Figure). Moreover, according to the mortality analysis of Johns Hopkins University, Mexico's observed case-fatality is on average 9.8\%, placing the country as the deadliest country using this indicator. If measured against population

\footnotetext{
${ }^{5}$ On testing, see "Tests per thousand since the 100th confirmed case of COVID-19" in Our World in Data. On the positivity rate, refer to "The share of COVID-19 tests that are positive" in Our World in Data.
} 
size, Mexico's deaths per 100,000 population stands at 75.3 , the fifth highest in the world ${ }^{6}$.

Figure 2: Deaths due to COVID-19

(a) Deaths from COVID-19

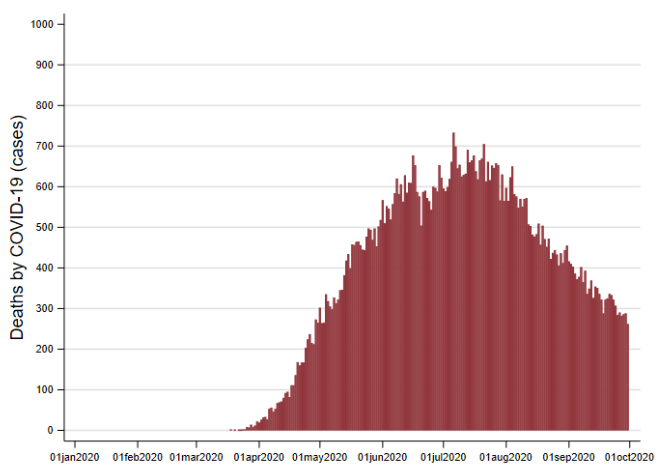

(b) Case-fatality ratio

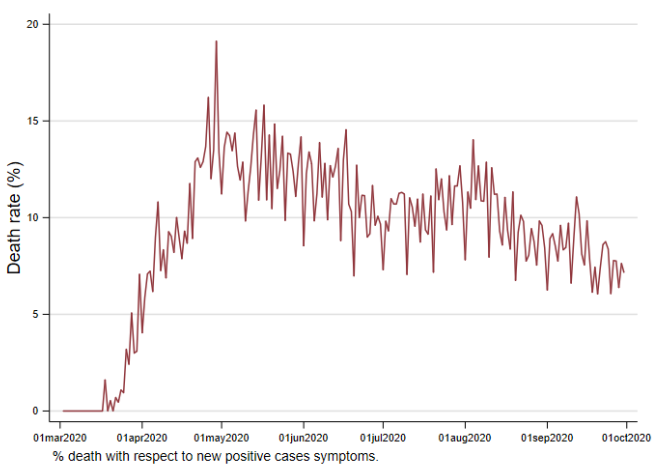

Notes: Authors' estimates using data from the General Directorate of Epidemiology from January to September, 2020. (a) shows reported daily death counts from confirmed COVID-19 cases. (b) shows the percentage of deaths with respect to confirmed COVID19 cases.

Despite knowing about the imminent pandemic in advance, the Mexican authorities did not respond quickly nor forcefully. Almost a month after confirming the first case, from March 23rd to May 30th 2020, the the Mexican Ministry of Health implemented the National Social Distancing Program (JNSD for its Spanish acronym: Jornada Nacional de Sana Distancia), consisting in emphasizing stay-at-home recommendations, social distancing and a series of non-pharmaceutical measures aimed at containing the 2020 coronavirus disease pandemic. ${ }^{7}$ However, the stay-at-home periods were a mere recommendation, for that reason leadership messaging became crucial in persuading the population to practice social distancing and stay at home, despite the high economic costs of doing so.

\footnotetext{
${ }^{6}$ Information retrieved on November 10, 2020 from https://coronavirus.jhu.edu/data/mortality

${ }^{7}$ The JNSD also entailed the closure of all non-essential activities and the cancellation of massive events. The non-pharmaceutical measures included: frequent and thorough hand-washing or use of hand sanitizers; sneezing and coughing etiquette and hand washing afterward; avoidance of handshakes, kisses, and hugs when greeting; avoidance of face touching (eyes, nose and mouse, in particular); and self-isolation in case of cough or fever.
} 
While COVID-19 czar HLG was constantly messaging the public about JNSD, President AMLO was still holding massive events in which he continued having physical contact with the population. Daverio Occhini et al. (2020) have documented that the President's public meetings over the country are associated with increased population mobility. Hence, there is a contradiction between the measures recommended by health authorities and the President's actions and his verbal messages. The President usually avoided mask use, the first time he wore a mask in public was during his official visit to the U.S. on July 7, 2020, and stopped its use afterwards. It is worth noting that AMLO reached the presidency with a very high public support. He thus had the potential to use his political capital to steer the public's behavior towards preventive measures. Similar concerns have been raised by research done in other countries: Ajzenman et al. (2020) find that after Brazil's president publicly and emphatically dismissed the risks associated with the COVID-19 pandemic and advised against isolation, the social distancing measures taken by citizens in pro-government localities weakened compared to places where political support of the president is less strong.

On June 1st, Mexico began using a color-coded system called the "COVID-19 traffic-light" $"$ to signal the local risk during the pandemic. ${ }^{9}$ The implementation of the COVID-19 traffic lights system shifted the policy discourse around the pandemic from a JNSD and strong stay-at-home recommendations to a "New Normality" coupled with a phase-in reboot of economic and social activities. The patterns in Google's mobility data, which show that cross-country mobility began increasing between May and June 2020 (Google, 2020), suggest that the policy discourse change changed the risk beliefs among the population, even in geographic areas where the red lights remained active. Perceived optimism in daily messaging may have been interpreted as substantial reductions in health risks and the end of the highest risk

\footnotetext{
${ }^{8}$ https://datos.covid-19.conacyt.mx/

${ }^{9}$ In this system, a red light implies that only essential activities can remain open, whereas the green light means "we are back to normal." Orange and yellow lights have guidelines on the type of activities that can reopen and at what capacity (for instance, under the orange phase, non-essential activities could reopen, but only at $30 \%$ capacity)
} 
scenario. In this paper, we are the first to show that when the COVID-19 czar's discourse is positive - potentially reflecting optimism-, mobility tends to decrease as compared to baseline.

Mexico's context further complicated compliance with stay-at-home recommendations. First, a little over half of the population works in the informal sector, and almost half of the population have incomes below the poverty line. People in the informal sector are less likely to have employment contracts, job stability, or safety nets and are more likely to have lower wages and no savings. Second, a sizable share of the population is unable to work from home. Monroy-Gómez-Franco (2020) documented that only 20 to $23 \%$ of workers can work from home, and they tend to be at the higher tail of the income distribution. Finally, the government did not implement policies that would enable people or businesses to stop working. Only the Ministry of the Economy modified a previously existing microcredits program to protect small businesses during the pandemic. By early October, the ministry had given 1.2 million credits of roughly 1,200 USD per business. Given this context, our research provides a glance of population behavior, where a large proportion does have the basic infrastructure, social protection, or income to comply with non-mandatory stay at home orders. This shows that in the trade-off between mobility and economic activity, some people have to be more mobile when they lack a safety net.

\section{Data}

Our research design uses several sources of data. Those include UNDP LAC-Grandata mobility, daily press conferences, and number of COVID-19 cases and fatalities. In this Section we describe the data and present relevant descriptive statistics.

\subsection{Geographical Mobility}

We use the UNDP-Grandata, obtained through the call for research proposals issued on August 2020. Since March 1st, GRANDATA has been collecting geolocation 
events of smartphone owners using a Mobile Advertising ID (MADID) "hash". These events track smartphone users' mobility patterns for a sizeable sample of the population of twelve Latin American and Caribbean countries.

Mobility indicators were constructed by GRANDATA, by dropping all home events and summing the number of "out-of-home" events for a particular region. We use municipality-level mobility data to estimate the relation of COVID-19-related health messaging and mobility containment. The data was weighted by municipal population size to obtain representative mobility indicators at the municipal level. Figure 3 presents the evolution of the mobility index changes with respect to March 1st, 2020. Mobility started to decrease in mid-March and reached its minimum around the start of the JNSD. Since then, mobility has varied, though it has not recovered to its pre-March level. We can also see the positive association of mobility and the "COVID-19 traffic lights" implementation in June.

Figure 3: Percentage change of the mobility index relative to March 1, 2020



Note: Authors' estimations using GRANDATA mobility data for Mexico. The figure shows the percentage change in the mobility index with respect to March 1, 2020 at the national level (estimated using population weights). 


\subsection{Discourse}

We web scrapped publicly-available stenographic versions of AMLO's and HLG's press conferences from the Mexican Presidency web site, from March 2020 to September 2021. Each series of conferences was then processed and classified through natural language processing algorithms. Figures 4 and 5 highlight the differences in content between these two conferences. ${ }^{10}$ As expected, "COVID press conferences" revolve around health topics, prevention measures, and information about the pandemic. In contrast, AMLO's daily press conferences have a wider range of topics besides the pandemic.

Figure 4: Word cloud - COVID press conference



Note: Figure shows the translated version of the wordcloud generated using all the COVID-19 press conferences held by Hugo Lopez-Gatell, the coronavirus czar of Mexico.

\footnotetext{
${ }^{10}$ The original analysis was conducted in Spanish, and the Spanish version of the word clouds is presented in Figures A.2 and A.3 in the Appendix.
} 
Figure 5: Word cloud - AMLO's daily press conference

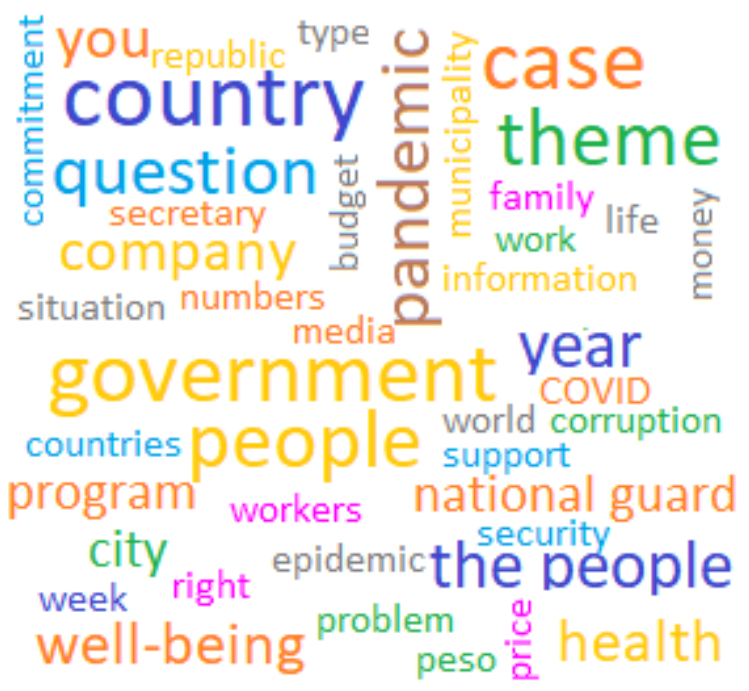

Note: Figure shows the translated version of the wordcloud generated using all the daily press conferences held by AMLO, the president of Mexico.

\subsection{COVID-19 Cases and Mortality}

Daily COVID-19 confirmed cases and deaths from COVID-19 are publicly available at the General Directorate of Epidemiology (Dirección Nacional de Epidemiología). All cases are introduced into the dataset on the date that they became suspicious for COVID-19. The data is updated to record whether the suspect case had a positive or negative lab test and whether the suspect case resulted in a fatality. We used the date of first symptoms as the date for each case. Over space, the data are geocoded at the municipality level. Thus, the final COVID-19 dataset is aggregated at the day-municipality level. ${ }^{11}$ Figures 1 and 2, previously shown, presented the trends of positive cases, fatalities and the case-fatality ratio.

\footnotetext{
${ }^{11}$ The COVID-19 dataset also collected information on patients' age, sex, ethnic origin and comorbidities, as well as variables that convey the severity of the case: whether the patient presented pneumonia, used a respirator, or was admitted to an intensive care unit.
} 


\subsection{Control Variables and Potential Sources of Heterogeneity}

To control for several potential confounders and sources of heterogeneity on the mobility responses to the public health discourse, we include measures of poverty, political affiliation, and experience with the $\mathrm{H} 1 \mathrm{~N} 1$ pandemic.

Economic factors have played an essential role in determining compliance during the COVID-19 pandemic in several regions (Wright et al., 2020). To measure poverty, we use several indicators with variation at the municipality level obtained from the 2015 Inter-Census data. The first is housing overcrowding, measured as the ratio of people per room within a household, where 2.5 or above indicates that the household is overcrowded. ${ }^{12}$ In addition, we use several sanitation measures at the household level, such as sewage, trash collection, and access to running water. Lastly, we also add a measure of access to broadband internet.

We proxy political affiliation using the 2018 federal electoral results at the municipality level, publicly available at the National Electoral Institute (INE) website. Using the results of these electoral races, we identified the winner, the percentage of votes the winner got, and the difference in the percentage of votes between the winner and the second place. Figure A.4 presents the winner of the Presidential, Senate, and Chamber of Deputies races by municipality. The darkest colors correspond to either the President or the President's party, National Regeneration Movement (MORENA for its Spanish acronym). Even though there was an intensive campaign to vote for a single party in all elections, the maps show voters split their votes in the different races. As a result, there is more variation in political preferences in the Senate and the Chamber of Deputies races.

Finally, data for the H1N1 pandemic local experience will be measured by the excess deaths from influenza and pneumonia during 2009 and 2010 at the municipality level. The mortality data comes from death certificates from the National System of Health Information (SINAIS), which record the cause of death using the Interna-

\footnotetext{
${ }^{12}$ This threshold is set by the National Council for the Evaluation of Social Development Policy (CONEVAL, for its Spanish acronym).
} 
tional Classification of Diseases and the municipality of residence. Since influenza H1N1 is not explicitly identified as the cause of death in this data, we estimated the accumulated death counts at the municipal level from influenza and pneumonia (ICD codes J09-J18) and pneumonia of unspecified origin (J18) from 1998 to 2010. Using the pre-H1N1 period, we estimated a prediction model for the number of influenza and pneumonia cases, ${ }^{13}$ which we then applied to 2009 and 2010. Lastly, using this prediction and the observed number of potential H1N1-cases, we estimated the excess deaths during the H1N1 pandemic. Figure A.5 presents the evolution of deaths from influenza and pneumonia (Panel a) and the distribution of these deaths across the territory (Panel b).

\section{Empirical Strategy}

We use automated text analysis to classify the content of 504 speeches by the President and the COVID-19 czar, whose transcriptions have been web scraped from the Mexican Presidency's press site. Using topic modeling and sentiment analysis, we quantify the prevalence and nature of COVID-19-related topics in these daily press conferences, as well the emotions that the discourse conveyed.

Our strategy consisted in, first using topic modeling to identify the changes in the priorities of press conference messages. Our approach to topic selection is datadriven, using latent Dirichlet allocation (LDA), as proposed by Blei et al. (2002): a three-level hierarchical Bayesian model. Each document is modeled as a combination of a finite set of topics. ${ }^{14}$ In a hierarchical Bayesian model, the distribution of certain parameters depends on other parameters within the model, so it is estimated at different levels hierarchically (Taboga, 2017). LDA assumes the existence of $k$ latent topics over which any document is generated. Each topic is represented as a Multinomial Distribution over the total number of words in any given vocabulary $|V|$ (in this case Spanish). In this way, a document that has been generated with

\footnotetext{
${ }^{13}$ The prediction model consisted on a linear regression with controlled for municipality fixed effects, municipality-specific time trends and state-specific month fixed effects.

${ }^{14}$ This assumption allows for topic probabilities to provide a full representation of the text.
} 
a subset of words from a given vocabulary has a mixture of latent topics. First, a document with $N$ words is generated in such a way that $\theta$ is taken from a Dirichlecht Distribution of the $k$ possible topics $\left(\alpha_{1}, \ldots, \alpha_{k}\right)(\theta \sim \operatorname{Mult}(\alpha)){ }^{15}$ Subsequently, for each of the $\mathrm{N}$ words $\left(w_{n}\right)$ we choose a topic $z_{n}$ sampled from a Multinomial Distribution such that $p\left(z_{n}=i \mid \theta\right)=\theta_{i}\left(z_{n} \sim \operatorname{Mult}(\theta)\right) .{ }^{16}$ Finally, each word $w_{n}$ is sampled conditioned on the distribution of the topic by $p\left(w_{n} \mid z_{n} ; \beta\right)$ where $\beta$ is a $k *|V|$ matrix and $\beta_{i j}=p\left(w_{j}=1 \mid z_{i}=1\right.$ ) (Blei et al., 2002, 2003). ${ }^{17}$ There are two important things to notice in our specific case, firstly we have 2 different vocabularies: one for AMLO's discourse and one for HLG's, this can cause the same word to be associated with different topics in each of the discourses; secondly the algorithm does not assign names to the topics, these were chosen by us taking the top 10 words and sentence examples into account.

The second step consisted in quantifying the content of the speeches. We used sentiment analysis to examine the shift in the emotions conveyed during the press conferences throughout the different stages of the pandemic. Sentiment analysis classifies a lexicon into the emotions they evoke and their valence (positive or negative). ${ }^{18}$ The emotions are classified into anger, anticipation, disgust, fear, joy, sadness, surprise, and trust through a lexicon, following Mohammad and Turney (2013). ${ }^{19}$ Then, we sum all of the times an emotion is evoked by a word in the document and divide it by the total of "effective words" in the document. ${ }^{20}$ The same procedure is done with the valence of the words, so that we have a relative measure of percentages

\footnotetext{
${ }^{15}$ Where $\theta$ lies in the $k-1$ dimension.

${ }^{16}$ From the Multinomial Distribution we know that $\theta_{i}>0$ and $\theta_{i} \in[0,1] \rightarrow \sum_{i=1}^{n} \theta_{i}=1$.

${ }^{17}$ The probability of a document can then be expressed as

$$
p(W)=\int_{\theta}\left(\prod_{n=1}^{N} \sum_{z_{n}=1}^{k} p\left(w_{n} \mid z_{n} ; \beta\right) p\left(z_{n} \mid \theta\right)\right) p(\theta ; \alpha) d \theta
$$

${ }^{18} \mathrm{~A}$ lexicon is a list of words; any given document can be divided as a list of words that are used to form the document.

${ }^{19}$ We use the lexicon provided by Jockers (2020) which is available through the syuzhet Rpackage.

${ }^{20}$ Note that a word can be associated with various emotions. The effective words are as the total number of words that evoke emotions.
} 
associated with each emotion and valence in each document.

The third step aimed to find the words, topics, and emotions that best predict mobility changes in Mexico. Merging the speech content and the UNDP LAC-Grandata mobility data, we use LASSO model selection to examine a) which topics mentioned in the conferences are the most associated with mobility patterns during the pandemic, and b) whether the emotions and their valence are correlated with mobility - and hence, compliance with stay-at-home recommendations.

Our central assumption is that, when we control for simultaneous cases at the municipality level, which rule the availability bias (Tversky and Kahneman, 1974), we can isolate the correlation of public health messaging on concurrent mobility and cases two weeks later. Since the political discourse may not affect every person in the same way, depending on factors such as the possibility to work from home or the ability to afford a period of inactivity, we use a quantile-regression approach (Koenker and Bassett Jr, 1978; Koenker and Hallock, 2001). Due to the high number of independent variables, we implement a data-driven approach to find the most relevant components of pubic discourse. Thus, we penalize our regression using the L1 norm (LASSO regression), as proposed by Yi and Huang (2017). Mobility changes are a function of the following linear model:

$$
Y_{m t}=\alpha+D_{t-1} \boldsymbol{\beta}+S_{t-1} \boldsymbol{\gamma}+W_{t-1} \boldsymbol{\delta}+C_{m} \boldsymbol{\theta}+\epsilon_{m t}
$$

where $Y_{m t}$ represents are mobility changes in municipality $m$ and day $t ; D_{t-1}$ is a vector of press conferences' topics in the previous day; $S_{t-1}$, a vector of conferences' sentiments; $W_{t-1}$, a vector of key words in the public health discourse; and $C_{m}$ are control variables, which include municipality level sociodemographic variables, political preferences, and H1N1 pandemic experience; and $\epsilon_{m t}$ is the error term.

For simplicity, let's redefine the vector of parameters to be estimated as

$$
\boldsymbol{\pi}=\left[\alpha, \boldsymbol{\beta}^{\prime}, \boldsymbol{\gamma}^{\prime}, \boldsymbol{\delta}^{\prime}, \boldsymbol{\theta}^{\prime}\right]
$$


and the matrix of explanatory variables as:

$$
X_{m t}=\left[\mathbf{1}, D_{t-1}, S_{t-1}, W_{t-1}, C_{m}\right]
$$

Then, the LASSO penalized quantile regression problem is given by:

$$
\min _{\boldsymbol{\pi}} \frac{1}{n} \sum_{m t} \rho_{\tau}\left(y_{m t}-X_{m t}^{T} \boldsymbol{\pi}\right)+\lambda \sum_{j}\left|\pi_{j}\right|
$$

where $\mathrm{n}$ is the number of observations (county-day), and $j \in(1, J)$ are the parameters to be estimated, contained in vector $\boldsymbol{\pi}$. The quantile loss function $\rho_{\tau}(l)$ for quantile $\tau$ is computed as:

$$
\rho_{\tau}(l)=l(\tau-I(l<0))
$$

In the model $l$ is replaced by residuals. We obtained a $\lambda$ of 0.001106 using 10 fold cross validation, which is considered small. ${ }^{21}$ Normally, when estimating machine learning models such as the Lasso Regression, one leaves one random part of the observations as a test or validation group, when dealing with time series specifically one tends to leave the last $n \%$ of observations out, since we have panel data with a time series component, we would have to follow this procedure. However, as will be seen in Section 4, as the pandemic evolved some topics became irrelevant, which could result in underestimating our parameters. To mitigate this, we estimated the model 100 times with a subset of our data to get robust estimations using bootstrap. This allows us to estimate confidence intervals for our parameters in order to get robust estimations. The aim of this strategy is to identify which topics, sentiments and words have a stronger association to mobility.

\footnotetext{
${ }^{21}$ When lambda is small, the result is essentially the least squares estimates. As lambda increases, shrinkage occurs so that variables that are at zero can be thrown away. So, a major advantage of lasso is that it is a combination of both shrinkage and selection of variables. In cases with very large number of features, lasso allow us to efficiently find the sparse model that involve a small subset of the features.
} 
We also test for heterogeneity in the response. The low-income population may be less able to protect themselves by following stay-at-home recommendations. We will proxy for poverty using dwelling overcrowding at the municipality level and the average availability of basic public services such as piped water, sewage, and trash collections in the municipalities households (Brown et al., 2020). In addition, we assess whether AMLO's or HLG's press conference have a differential association by political affiliation, as has been documented in other countries (see Allcott et al. (2020); Barbieri and Bonini (2020) 2020; Barrios and Hochberg (2020); and MacMillen (2020)). Finally, we estimate whether the relationship between mobility patterns and messaging is different in municipalities with higher death tolls from H1N1 in 2009. We hypothesize that municipalities with high pandemic-related mortality rates from H1N1 have more information on the burden of disease and will be more responsive to safety measures during the COVID-19 pandemic and less inclined to guide themselves by political ideology. Evidence on the effectiveness of policy messaging at generating population-level behavior change can shed light on the efficacy of stay at home orders, the timing of when these can safely be relaxed, and perhaps the geographical locations where enforcement efforts should be emphasized.

\section{Results}

Our results are presented in the following order. We first discuss our analyses of the evolution of AMLO's and HLG's discourses. Next, we discuss the results from the quantile regressions. We conclude with a reflection on potential mechanisms and a test for reverse causality.

\subsection{Evolution of Discourse}

The first step of our text analysis was to conduct a sentiment analysis to identify whether there was variation in the emotions conveyed by the press conferences. Figure 6 presents our findings. Both conferences have a predominantly positive tone. However, AMLO's conference exhibits more variation than HLG's conference. Fig- 
ure 7 presents the emotions' composition of both conferences. The main sentiment conveyed in both conferences is trust. However, there are some differences between AMLO and HLG. Again, AMLO displays much more variation than HLG in his emotions; anger, fear, and surprise are the emotions that present the most variation. Besides trust, anticipation, fear, and sadness are the predominant emotions in both sets of speeches.

Figure 6: Daily sentiment valence of the press conferences

(a) AMLO's



(b) COVID-19

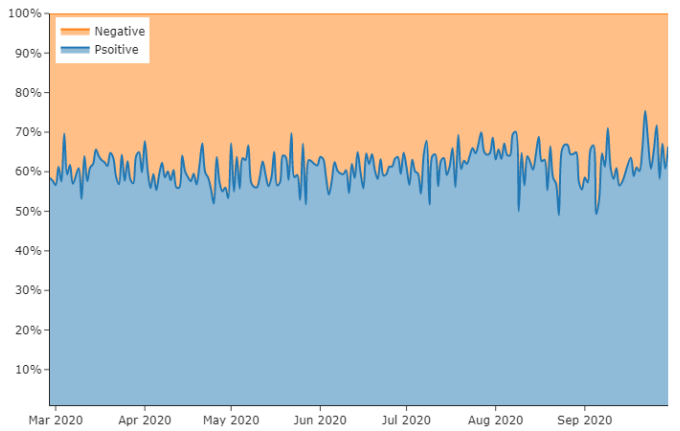

Notes: Authors' estimates using data from the stenographic versions of the COVID19/López Gatell's press conference and AMLO's daily press conference. Each graph presents the valence composition of the conferences over the whole period of analysis: March 1, 2020 to September 30, 2020.

Using topic modeling, we classified the conferences' discourse into its central themes. In the case of AMLO's press conferences, our data-driven approach to topic identification distinguished four main topics with a coherence score of 0.38 : the economy, COVID-19, security, and public policy. ${ }^{22}$ In contrast, in the COVID19 press conferences, we identified five main topics with a coherence score of 0.36 :

\footnotetext{
${ }^{22}$ Topics are coherent if the topic's top $\mathrm{N}$ words are related. We use $C_{V}$ as a measure of coherence as proposed by Syed and Spruit (2017) . $C_{V}$ is a 4-step algorithm in which each of the top N words is segmented and paired with every other top $\mathrm{N}$ word. Subsequently, we calculate probabilities for those segments by counting the number of documents each word occurs divided by the total number of documents. Once we have all the probabilities, we estimate a measure of confirmation through the similarity of the distribution of the top $\mathrm{N}$ words via normalized pointwise mutual information (NPMI). The final coherence score is the arithmetic mean of all confirmation measures $\phi$.
} 
Figure 7: Daily sentiment valence of the press conferences

(a) AMLO's

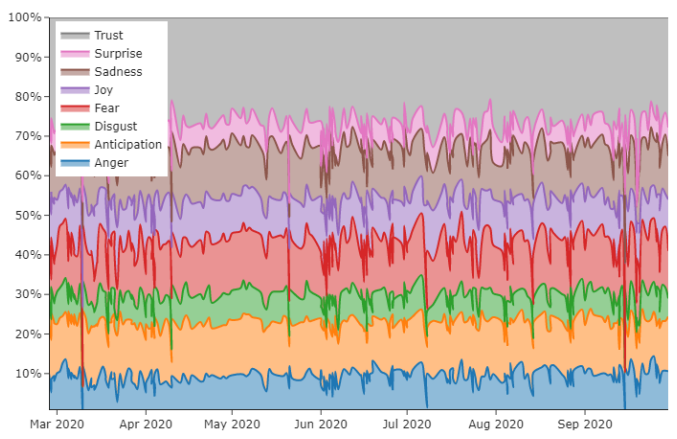

(b) COVID-19

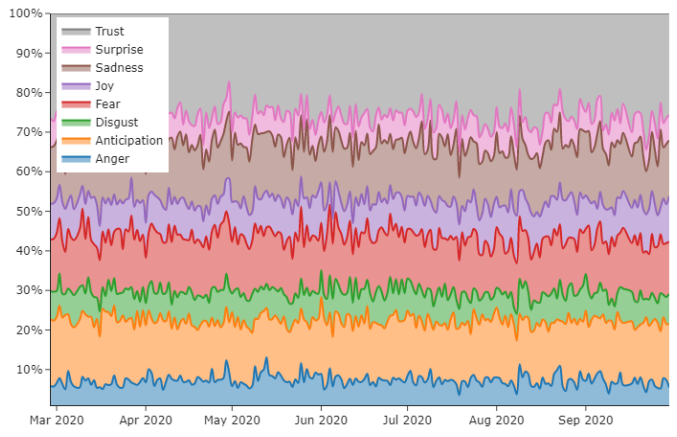

Notes: Authors' estimates using data from the stenographic versions of the COVID19/López Gatell's press conference and AMLO's daily press conference. Each graph presents the composition of emotions conveyed in the press conferences over the whole period of analysis: March 1, 2020 to September 30, 2020.

measures, mobility, maternity, vaccines, and information on the pandemic status in Mexico. Appendix Table B.1 presents the words most commonly associated with each of those topics for the press conferences, along with an illustrating example of a sentence classified in that topic.

Figure 8 presents the frequency per topic. In AMLO's case (Panel a), the economy is the prevailing topic in his morning conferences, followed by security, public policy, and COVID, in that order. The COVID-19's press conference placed a greater emphasis on mobility restrictions, the provision of information about the epidemic in Mexico, and then vaccines, health measures, and lastly maternity issues. ${ }^{23}$

$$
\begin{gathered}
\vec{v}\left(W^{\prime}\right)=\left\{\sum_{w_{i} \in W^{\prime}} \operatorname{NPMI}\left(w_{i}, w_{j}\right)^{\gamma}\right\}_{j=1, \ldots,|W|} \\
\operatorname{NPMI}\left(w_{i}, w_{j}\right)^{\gamma}=\left(\frac{\log \frac{P\left(w_{i}, w_{j}\right)+\epsilon}{P\left(w_{i}\right) * P\left(w_{j}\right)}}{-\log \left(P\left(w_{i}, w j\right)+\epsilon\right.}\right) \\
\phi_{S_{i}}(\vec{u}, \vec{w})=\frac{\sum_{i=1}^{|W|} u i * w i}{\|\vec{u}\|_{2} *\|\vec{w}\|_{2}}
\end{gathered}
$$

${ }^{23}$ HLG did not talk about maternity very often, but it is classified separately because its content 
Figure 8: Overall topic composition of the press conferences

(a) AMLO's

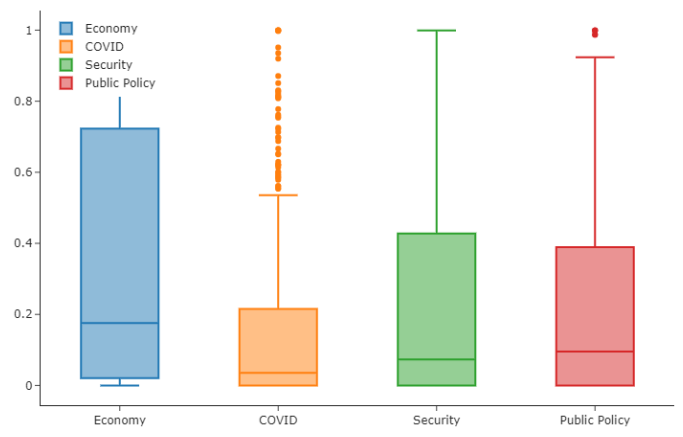

(b) COVID-19

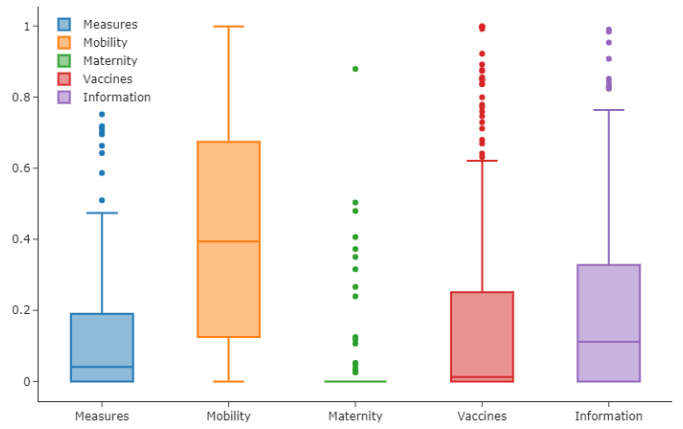

Notes: Authors' estimates using data from the stenographic versions of the COVID19/López Gatell's press conference and AMLO's daily press conference. Each graph presents the weekly average topic composition of the conferences over the whole period of analysis: March 1, 2020 to September 30, 2020. The topics were identified via topic modelling (see Appendix Table B.1).

Over time, however, there is a wide variation on the topics that AMLO and HLG emphasize in their corresponding press conferences. Figure 9 shows the topic composition of both press conferences. Panel (a) shows that the economy dominated AMLO's at the beginning of the pandemic, but as the situation evolved, the public policies and COVID-19 references became more prevalent. In HLG's conferences (Panel b), health measures dominated at the beginning of the pandemic, but this pattern quickly shifted towards mobility messaging. Mobility messaging itself displays variation over the period of analysis with peaks and troughs over the last 15 weeks. As the pandemic progressed, by week 30 of the year, vaccines started to take more importance in the discourse. Finally, one of the COVID-19 press conference objectives is to inform the population about daily changes in positive, suspicious, and fatality cases. Between weeks 22-28, the discourse centered more on providing information, along with mobility messages.

is very different from the rest. 
Figure 9: Weekly topic composition of the press conferences

(a) AMLO's



(b) COVID-19

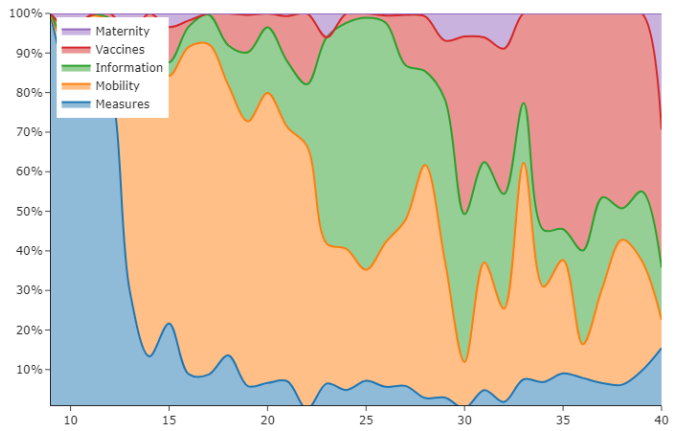

Notes: Authors' estimates using data from the stenographic versions of the COVID19/López Gatell's press conference and AMLO's daily press conference. Each graph presents the topic composition of the conferences on a weekly basis from March to September, 2020. Week 9 represents the first week of March, 2020. The topics were identified via topic modelling (see Appendix Table B.1).

In our analysis, we identify some frequently-used keywords to which the population may potentially respond. These words and phrases were: epidemic, pandemic, safe distance, and stay-at-home. We group other frequently used and policy-relevant words into four categories: scientific messaging (for example, communicating the scientific aspect of how transmission works), control measures, vaccines, and testing. Figure 10 presents some interesting findings yielded by this analysis. ${ }^{24}$ The first noteworthy result is that AMLO has never mentioned "stay-at-home" (Panel a in yellow) in his press conference even though this recommendation is one of the key COVID-19 prevention levers worldwide. On his part, HLG starkly toned down this message throughout the pandemic, going down from more than 30 mentions at the peak relevance of this topic to less than five at the end of the period of analysis (Panel b in yellow). Social distancing is another key component of public health measures to prevent contagion. Both the president and his COVID-19 czar strongly conveyed this message, though they have both toned it down in the last ten weeks of our period of analysis. The bottom Panel II presents the comparisons between the

\footnotetext{
${ }^{24}$ Figure A.6 in the Appendix presents the other keywords.
} 
mentions of "vaccines" \& "tests." Vaccines have taken a greater importance in the COVID-19 press conference during the last couple of weeks of the analysis period, reaching a striking number of weekly mentions that surpasses 140 . In contrast, the word "tests" has been constantly mentioned, though it has exhibited some variation in both AMLO and HLG's conferences.

Figure 10: Evolution of keywords in the press conferences

I. Safe distance vs. Stay-at-home

(a) AMLO's

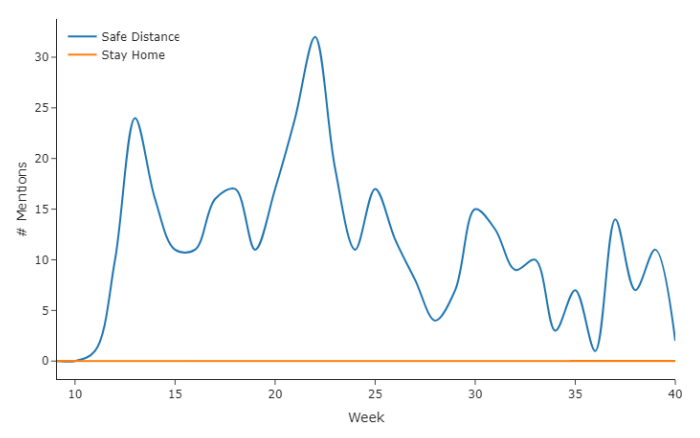

II. Vaccine vs. Test

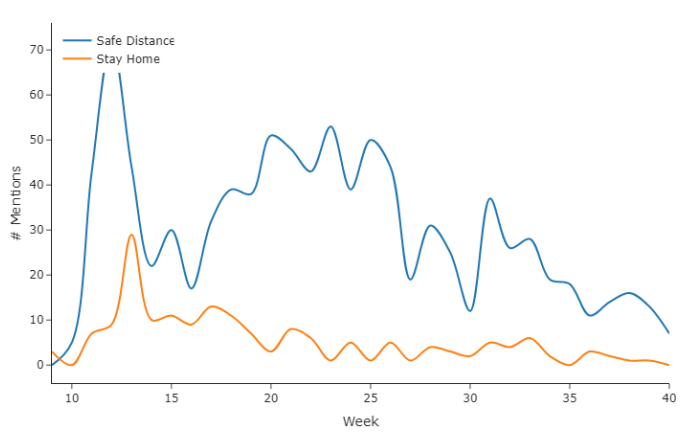

(c) AMLO's

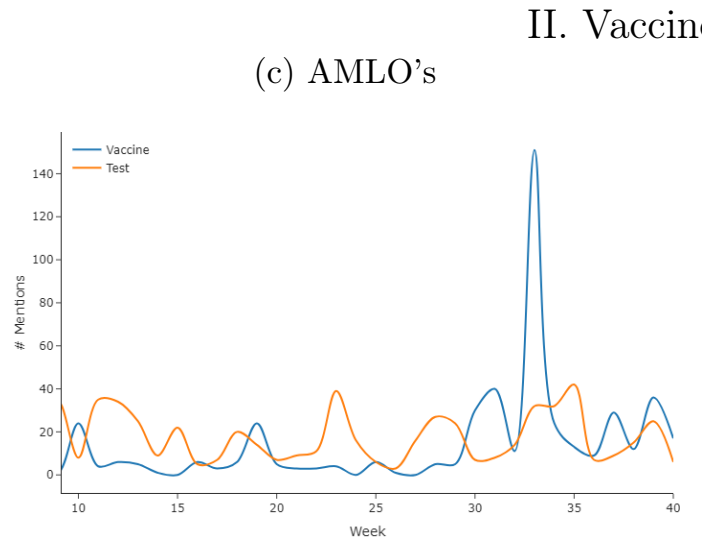

(b) COVID-19

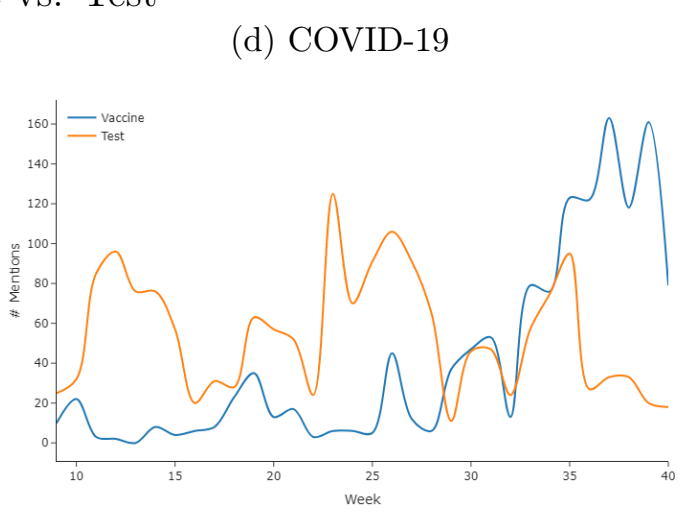

Notes: Authors' estimates using data from the stenographic versions of the COVID19/López Gatell's press conference and AMLO's daily press conference. Each graph presents the evolution of weekly mentions of two keywords over the period of analysis: March 1, 2020 to September 30, 2020. The top, Panel I, presents mentions of "Safe distance" (in blue) and "Stay-at-home" (in yellow). The bottom, Panel II, shows mentions of "Vaccines" (in blue) and "Tests" (in yellow). 


\subsection{Quantile Regression Results}

Figures 11 to 14 present the coefficient estimations of equation 4, the LASSO penalized quantile regression. We split the coefficient estimates into different figures for ease of presentation. However, all the results come from the same regression. The first set of results shows the association between mobility changes and discourse valence. ${ }^{25}$ As Figure 11 shows, whenever AMLO's discourse is positive, mobility tends to decrease compared to March 2, 2020.

In contrast, when HLG is positive in his COVID-19 conference, mobility increases relative to March 2, 2020. ${ }^{26}$ Moreover, across the distribution of mobility changes, those in the inter-quantile range are more responsive to the discourse. The largest response, observed for the the 2nd quintile in Panel a), is predicted to be a 1.2 percentage point (pp) decrease in mobility. This effect is roughly $5.4 \%$ of the average mobility change observed during the pandemic. Hence, while the effect of discourse is not very large, it is not negligible in a context where any reduction in mobility helps prevent disease spread, potentially saving lives, and health messaging is virtually cost-less as it is incorporated into daily press conferences. This heterogeneity in behavior across quantiles is observed across the results presented below. ${ }^{27}$

\footnotetext{
${ }^{25}$ Russell $(1980,2003)$ argued that the three primary independent dimensions of emotions are valence or pleasure (positiveness- negativeness/pleasure-displeasure), arousal (active-passive), and dominance (dominant-submissive). He argues that individual emotions such as joy, anger, and fear are points in a three-dimensional space of valence, arousal, and dominance. In this paper, we focus on valence because it is the most relevant dimension in analyzing press conferences.

${ }^{26}$ Given the mobility measure, our dependent variable, is calculated as a percentage change with respect to March 2, 2020, all of the coefficient estimates are interpreted as a change with respect to this date. We will omit this precision henceforth.

${ }^{27}$ In fact, the presence of this heterogeneity justifies our use of quantile regressions. When we estimated equation 1 with ordinary least squares (results not shown, but available upon request), the estimates at the mean masked the differences in the associations across the mobility distribution. In fact, these differences canceled out at the mean.
} 
Figure 11: Main results: Association between mobility and discourse valence

(a) AMLO's



(b) COVID-19

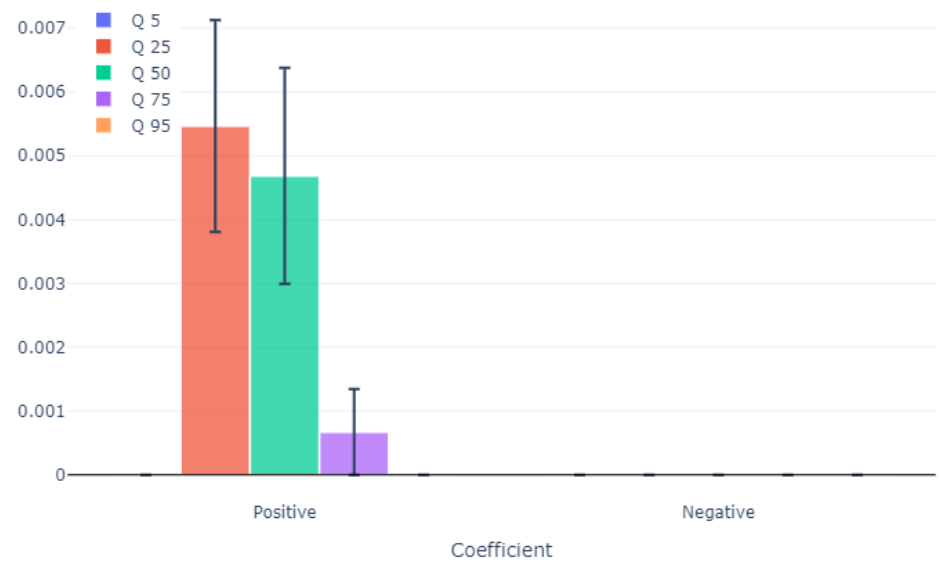

Note: Authors' estimates. Each bar represents a coefficient from the LASSO penalized quantile regression in equation 4 , where the dependent variables is the change in mobility (GRANDATA) and the main variables of interest are defined by AMLO's and López Gatell discourses in their respective press conferences (stenographic versions of the press conferences from Mexico's Presidencia web site). The discourse variables are presented in the x-axis. The estimations include controls for sociodemographic characteristics at the municipality level (2015 Inter-Census data), political preferences (2018 Federal Elections from INE's data), and previous experience with the H1N1 pandemic (death certificates data from SINAIS). 95\% confidence intervals are shown. 
When looking at the association between mobility and emotions (see Figure 12, the public responds differently to emotions conveyed in AMLO's discourse and that of the COVID-19 press conference. Whenever AMLO expresses joy or surprise, mobility tends to increase, whereas mobility tends to decrease if he expresses anticipation or disgust. As opposed to AMLO, if HLG conveys anticipation or disgust in his discourse, mobility increases though only at the lower tail of the mobility distribution. Mobility is negatively associated with sadness and trust in HLG's speech. A key finding of this exercise is that mobility is associated with a broader range of emotions in HLG's discourse: we found a positive correlation between mobility and fear, joy and surprise, with the most considerable effects exhibited when HLG conveys fear.

Figure 13 presents the association between mobility and the thematic categories generated through topic modeling in the press conferences' discourses. The topics that we identified for AMLO are: economy, security, public policy, and COVID-19; and for HLG: information, mobility, measures, vaccines, and maternity. For AMLO's estimations (the first three topics in the figure), the base category with respect to which we estimated the effects of other issues was "economy." Economy is the base category because it is the most common topic in AMLO's conferences. Hence the coefficients presented in Figure 13 are interpreted as the effect of deviating from the base topic, which is the economy. Some words among the top ten in this topic are "pesos, companies, money, agreement". ${ }^{28}$

Similarly, for HLG's conference, the base category, entitled "information," encompasses the statistical information provided by the COVID-19 czar on the progression of the pandemic in the various states and counties of Mexico. Some words included in this category are "trend, deaths, decrease, increase, and percentage." First, we found virtually no association between mobility and AMLO's discourse. As opposed to that, HLG's topics have prediction power on mobility changes. For instance, the topic mobility is associated to around a 5pp decrease in mobility at the 75th percentile. However, measures is the predominant topic in HLG's discourse, it predicts between 2-8pp increase in mobility in the interquartile range of the mobility

\footnotetext{
${ }^{28}$ For more information on topic composition, see Appendix Table B.1
} 
Figure 12: Main results: Association between mobility and discourse emotions

(a) AMLO's

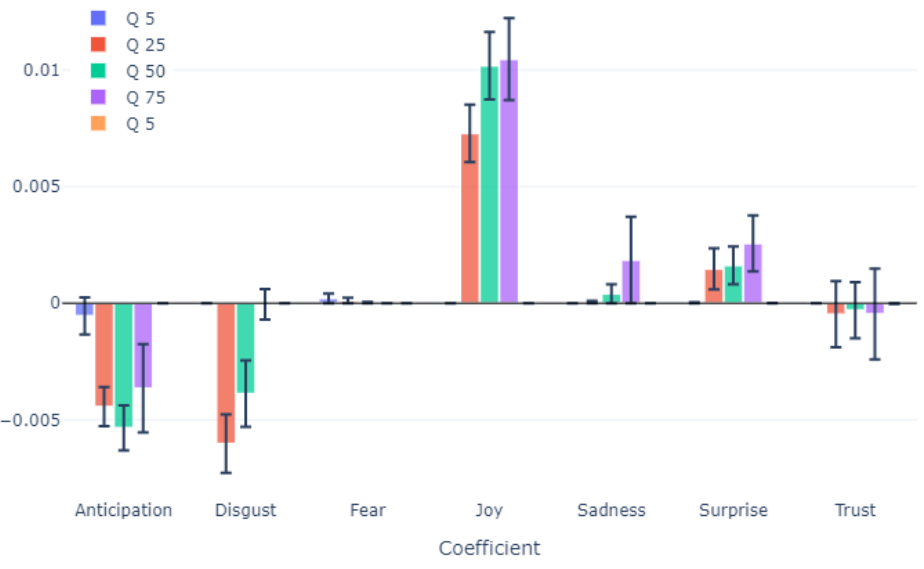

(b) COVID-19

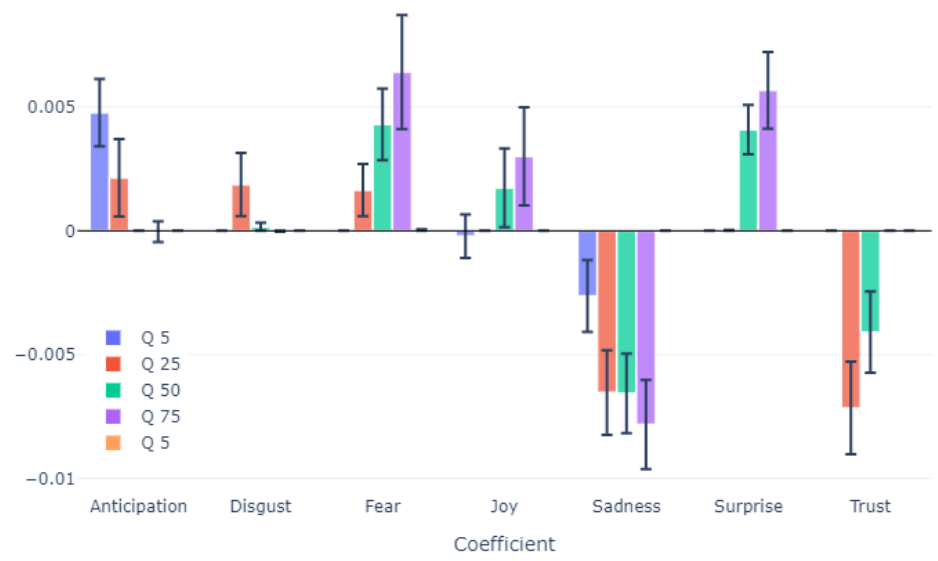

Note: Authors' estimates. Each bar represents a coefficient from the LASSO penalized quantile regression in equation 4, where the dependent variables is the change in mobility (GRANDATA) and the main variables of interest are defined by AMLO's and López Gatell discourses in their respective press conferences (stenographic versions of the press conferences from Mexico's Presidencia web site). The discourse variables are presented in the x-axis. The estimations include controls for sociodemographic characteristics at the municipality level (2015 Inter-Census data), political preferences (2018 Federal Elections from INE's data), and previous experience with the H1N1 pandemic (death certificates data from SINAIS). 95\% confidence intervals are shown. 
distribution, with the most considerable effect on the 25 th percentile.

Figure 13: Main results: Association between mobility and discourse topics

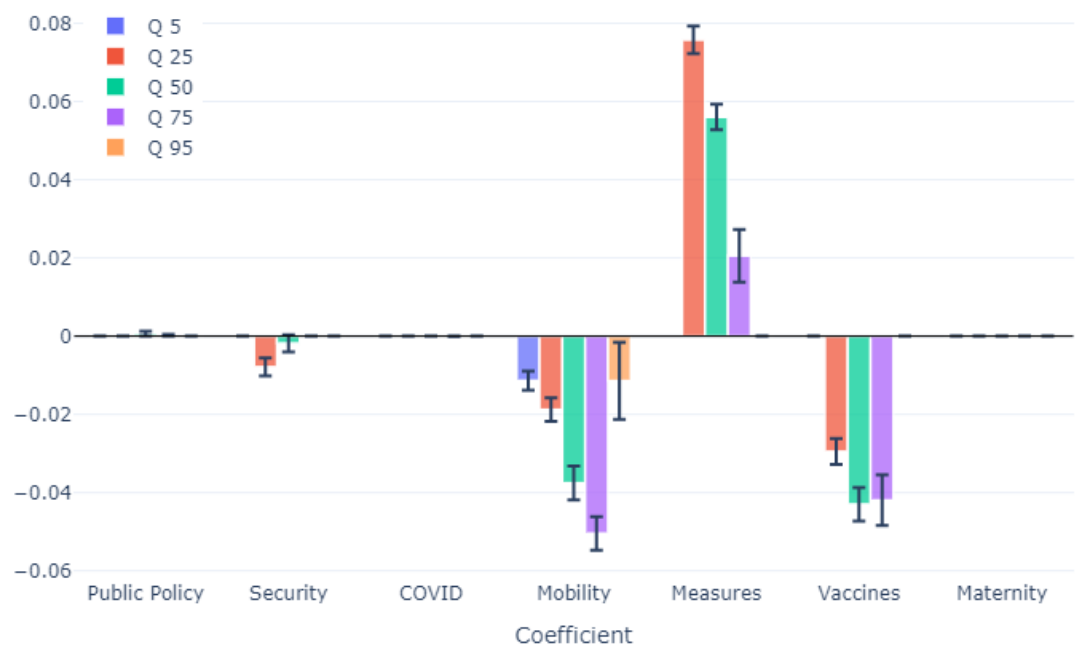

Note: Authors' estimates. Each bar represents a coefficient from the LASSO penalized quantile regression in equation 4, where the dependent variables is the change in mobility (GRANDATA) and the main variables of interest are defined by AMLO's and López Gatell discourses in their respective press conferences (stenographic versions of the press conferences from Mexico's Presidencia web site). The discourse variables are presented in the x-axis. The estimations include controls for sociodemographic characteristics at the municipality level (2015 Inter-Census data), political preferences (2018 Federal Elections from INE's data), and previous experience with the H1N1 pandemic (death certificates data from SINAIS). 95\% confidence intervals are shown.

Figure 14 presents the association between the critical policy words and mobility. The mention of "stay at home" on the COVID-19 press conferences predicts a slight decrease in mobility, only for the 75 th percentile of the mobility distribution. ${ }^{29}$ AMLO's mentions of "safe distance" predict a much larger mobility reduction than HLG's, albeit both coefficients are small in magnitude. Usage of the word "vaccines" has very little prediction power on mobility: the effect is only statistically significant in AMLO's case and just for the mobility distribution median. Finally, mentions of

${ }^{29}$ AMLO never mentioned "stay at home" in his morning conferences, so these words are excluded from the analysis of his conferences. 
"tests" predict reduced mobility in AMLO and HLG's conferences, but with a more considerable predictive power in AMLO's mentions. In sum, AMLO's usage of key policy words predicts a reduction in mobility, which is higher in magnitude than that predicted by HLG's mentions. This finding is critical in terms of discourse as public policy. While the prediction power of keywords is small in magnitude, once controlling for topics in general and other predictors, it has a consistent direction across messengers. Thus, both AMLO and HLG can reinforce each other's message.

Figure 14: Main results: Association between mobility and discourse keywords

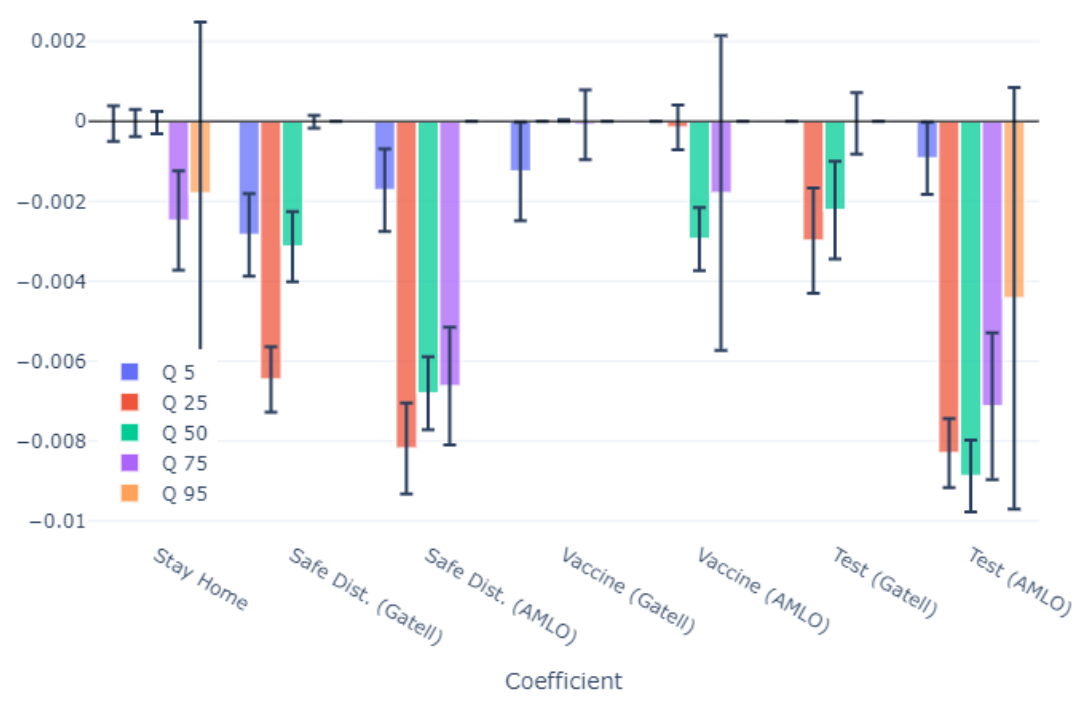

Note: Authors' estimates. Each bar represents a coefficient from the LASSO penalized quantile regression in equation 4 , where the dependent variables is the change in mobility (GRANDATA) and the main variables of interest are defined by AMLO's and López Gatell discourses in their respective press conferences (stenographic versions of the press conferences from Mexico's Presidencia web site). The discourse variables are presented in the $\mathrm{x}$-axis. The estimations include controls for sociodemographic characteristics at the municipality level (2015 Inter-Census data), political preferences (2018 Federal Elections from INE's data), and previous experience with the H1N1 pandemic (death certificates data from SINAIS). 95\% confidence intervals are shown.

Figure 15 presents the association between two sets of poverty-related measures and mobility. On the left-hand panel, the evidence shows a small decrease in mobility across the 25th to 75 th quantiles of mobility for individuals who live in counties with access to the internet. There are substantial drops in mobility for individu- 
als in the top percentile of the mobility distribution that live in places that have access to garbage collection and functioning sewage. For individuals in areas with access to running water, there is an increase in mobility among those in the highest mobility distribution percentile. In terms of marginalization by housing overcrowding, individuals that live in counties with a high share of overcrowded households are predicted to increase their mobility in the 75th and 95th percentiles of the mobility distribution, with the most massive effect observed in the top. All of these results together indicate that the individuals surrounded by the most disadvantaged environments are not in compliance with the stay-at-home ordinances.

Figure 15: Main results: Association between mobility and poverty (sanitation and marginalization by housing overcrowding)

(a) Sanitation and Internet Access

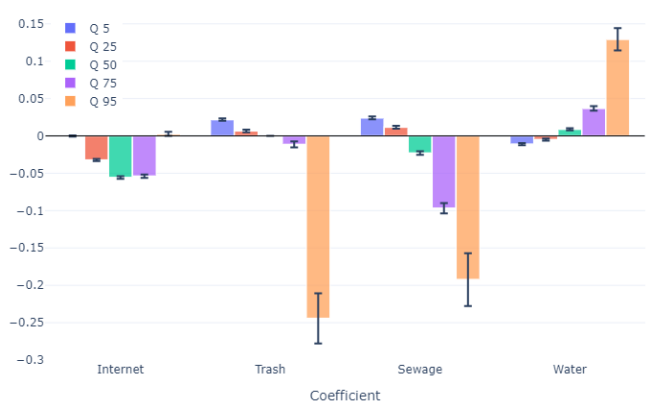

(b) Housing Overcrowding

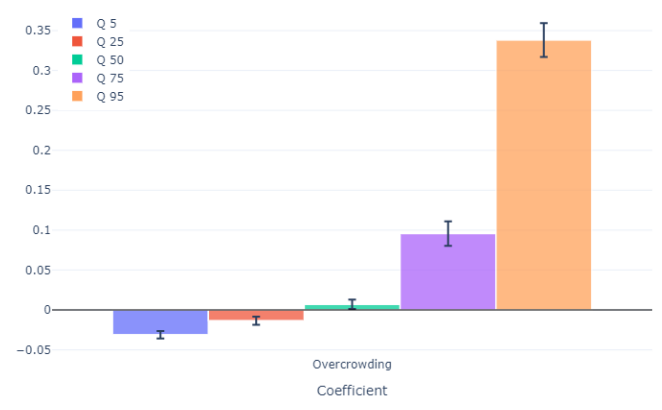

Note: Authors' estimates. Each bar represents a coefficient from the LASSO penalized quantile regression in equation 4, where the dependent variables is the change in mobility (GRANDATA) and the main variables of interest are defined by AMLO's and López Gatell discourses in their respective press conferences (stenographic versions of the press conferences from Mexico's Presidencia web site). The variables are presented in the $\mathrm{x}$-axis. The estimations include controls for sociodemographic characteristics at the municipality level (2015 Inter-Census data), political preferences (2018 Federal Elections from INE's data), and previous experience with the H1N1 pandemic (death certificates data from SINAIS). 95\% confidence intervals are shown. 


\section{Mechanisms}

With our current regression approach, we have defined that mobility changes are indeed associated to changes in the topic composition of press conferences and to mentions of certain words and phrases. We hypothesize that changes in mobility can be affected by government messaging through different mechanisms. Firstly, people who see the daily morning reports or the COVID reports may be more aware of the current situation due to the new information presented every day. ${ }^{30}$ Second, people who are more affiliated to a politician or political party's ideology may take more action in response to the speech given by the president and its team. ${ }^{31}$

\subsection{Direction of Causalities}

We hypothesize that people react to public officials' discourse and health messaging through awareness of specific topics - proxied by google searches - and political affiliation - proxied by electoral results. However, to prove these hypotheses, we need to show that discourse and awareness cause mobility and not the other way around. To that end, in this Section we show, using a Seemingly Unrelated Regressions system (SUR), that mobility changes in $t-1$ to $t-2$ do not predict HLG's discourse topics. ${ }^{32}$

Our SUR model consists on six equations: (1) COVID-19 positive cases, (2) COVID-19 fatalities, (3) Mobility changes, (4) HLG mobility topic, (5) HLG's measures topic, and (5) AMLO's COVID-19 topic. Both COVID-19 cases and fatalities may respond to past mobility changes and, if effective, public health messaging. At the same time, mobility may respond to information on COVID-19 cases and deaths, and, if effective, to the press conferences' discourse. Finally, the discourse may adapt

\footnotetext{
${ }^{30}$ Viewership is proxied by the views of each conference in the government's official YouTube account.

${ }^{31}$ We approximate political affiliation through state level 2018 electoral results for presidential and senatorial elections.

${ }^{32} \mathrm{SUR}$ is a generalization of a linear regression model that consists of several regression equations, each having its own dependent variable and potentially different sets of exogenous explanatory variables. Each equation is a valid linear regression on its own and can be estimated separately, but the error terms are assumed to be correlated across the equations.
} 
itself to the evolution of the pandemic (cases and deaths), as well as the public's geographical mobility in the past few days. All this feedback makes it very hard to give a causal interpretation to our results, specially if discourse is affected by past mobility.

Appendix Table B.2 presents the estimates of the SUR model. ${ }^{33}$ First, positive cases and fatalities have a limited association with mobility in the past three weeks. The association is clearer in the case of fatalities, where we find that an increase in mobility five days ago is related to an increase in deaths of people who presented symptoms today. ${ }^{34}$ On its part, mobility in $t$ has a high auto-correlation with mobility in the previous four days, a very small relation to positive cases and deaths, and it is only associated to HLG's measures topic. ${ }^{35}$ More importantly, HLG's discourse topics do not respond to mobility in the past two days; the coefficients are not statistically significant at a 5\% level. AMLO's discourse seems to respond, but, as we previously showed, mobility does not correlate to AMLO's messaging thus potentially breaking the potential reverse causality.

Another interesting finding in the SUR model is how AMLO's and HLG's discourses react to each other. ${ }^{36}$ AMLO's daily press conference takes place every work-day morning, whereas HLG's happens every day at 7pm. In the model, we test whether AMLO's COVID topic is related to what HLG said the evening of the previous day. Similarly, we test whether HLG's conference topics relate to what AMLO said in the morning that same day and in the previous day. HLG's mobility topic responds to what AMLO said about COVID that same morning, whereas the measures topic is unrelated to AMLO's COVID talk. Furthermore, AMLO's COVID talk does not related to HLG's mobility topic in the previous day, but it does cor-

\footnotetext{
${ }^{33}$ Appendix Table B.3 presents the Breusch-Pagan test that shows that indeed the errors across the equations in the system are not independent.

${ }^{34}$ Recall that both positive cases and deaths are time-indexed to the date when they first presented symptoms.

${ }^{35}$ These results may conflict with those presented in Section 4.2 because the heterogeneity of the estimates across the mobility distribution cancels out at the mean, and in those estimates we were only looking at the previous day messaging in the press conferences.

${ }^{36}$ We thank an anonymous referee for this suggestion.
} 
related to the measures topic in the previous day. In sum, the messengers seem to respond to each other, but with the current design we are unable to conclude if they are reinforcing the message or counteracting it.

To test whether the press conferences were endogenous to mobility in the past day, we also devised an instrument and a alternative endogeneity test. We will explain this alternative approach in Subsection 5.4.

\subsection{Awareness}

The COVID-19 is the first pandemic in the digital age, which has an unprecedented impact on the speed in which news travel and the effect that communications from the authorities can have if they harness the power of social media and digital communication. This section explores the association between discourse and public awareness. We measure awareness using search indexes from Google Trends, which are constructed by normalized raw search results to the time and location of a query. Each data point is divided by the total searches of the geography and time range it represents to compare relative popularity. The resulting numbers are then scaled on a range of 0 to 100 based on a topic's proportion to all searches on all issues. Figure 16 shows a comparison between searches for "stay at home" (in yellow) and "safe distance" (in blue) and AMLO's and HLG's mentions of those two key containment policies. Google searches for "stay at home" were high early in the pandemic and have substantially decreased following a pattern similar to that of HLG's mentions of these key policy words in his press conferences. Searches of "safe distance" have remained relatively stable and do not seem to follow either AMLO's or HLG's mentions. 
Figure 16: Interest/awareness on the words "safe distance" and "stay at home"

(a) AMLO's conferences conferences

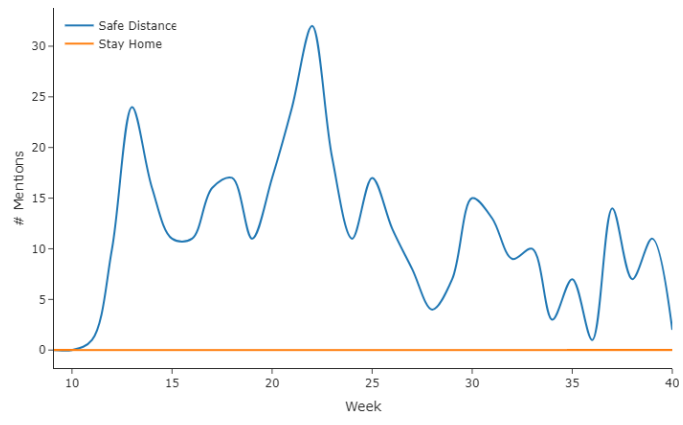

(b) COVID-19 conferences conferences

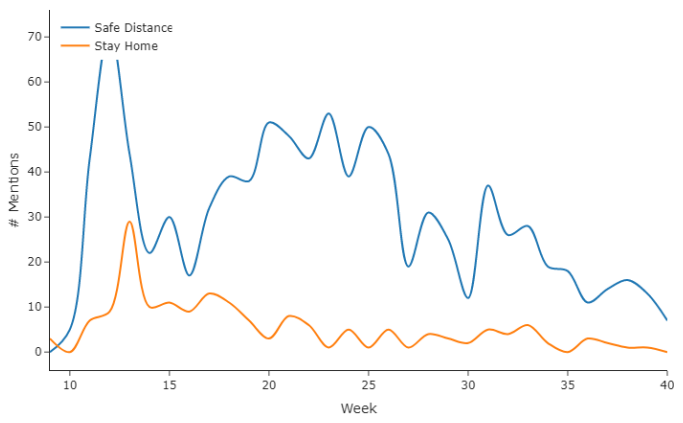

(c) Google searches

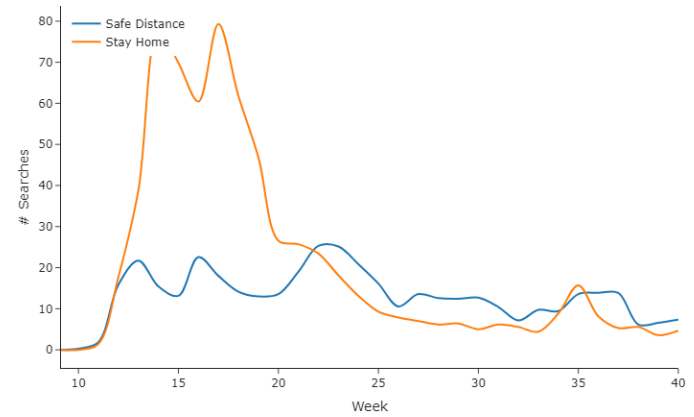

Note: Authors' estimates using data from the stenographic versions of the COVID19/López Gatell's press conference and AMLO's daily press conference. Each graph presents the evolution of weekly mentions of two keywords over the period of analysis: March 1, 2020 to September 30, 2020. The top, Panel I, presents mentions of "Safe distance" (in blue) and "Stay-at-home" (in yellow). The bottom, Panel II, shows mentions of "Vaccines" (in blue) and "Tests" (in yellow). Panel (c) presents the Google trends' index for "safe distance" and "stay at home" searches in Google.

Figure 14 shows that discourse is associated to awareness on key pandemic-related topics. Using Google searches at the national level as the dependent variable in a model in which awareness is a function of exposure to the conferences, we find that when more people see the President's daily conference, the word "Pandemic" (predominantly used by the president as shown in Appendix Figure A.6 (a)) has a higher number of searches. In comparison, the same happens when more people watch HLG's conference and the word "Epidemic" (predominantly used by HLG 
as shown in Appendix Figure A.6 (b)). Seemingly, searches for terms like Vaccine, Test, Safe Distance, Stay Home, and COVID-related words have a positive and significant association with views of the HLG's conference. In contrast, almost none of them have a significant association with AMLO's speeches, which would be logical given both conferences' topic distribution. These results are shown in detail in the Appendix in Table B.4.

Figure 17: Association between google searches and youtube views of AMLO and COVID conferences



Note: Authors' estimates. Each bar represents a coefficient from the OLS regression for Google Searches of COVID-19 related words and daily views of both AMLO's (red) and COVID-19's (blue) conferences. Only statistical significant coefficients are shown.

\subsection{Political Affiliation}

As reviewed in Section 1, people who have a stronger affinity for a particular political party or candidate are expected to react positively to the messages conveyed by that public figure. In contrast, people who identify less with the governing party or candidate are less expected to follow the party members or representatives' advice. To test these hypotheses, we look at the association of state-level google searches on 
electoral results. Figure 18 shows that in states where PAN won the senate, fewer people look for Pandemic, Epidemic, Vaccine, Test, and Mask compared to states where the majority voted for the MORENA party (the president's political party), while more people looked for the word Coronavirus. A similar trend is observed in states where Movimiento Ciudadano (MC) had a majority of Senate votes. In these states, the terms Epidemic, Vaccine, Test, Traffic Light, and Mask were looked up less than in states where the MORENA party won, while words like Safe Distance, Stay Home, and COVID related words had more searches. Overall, in states where the president's party lost, people look up fewer words associated with the pandemic, except for the terms that were never used by AMLO, such as "Stay at home". These results are shown in detail in the Appendix in Table B.4.

Figure 18: Association between google searches and election results

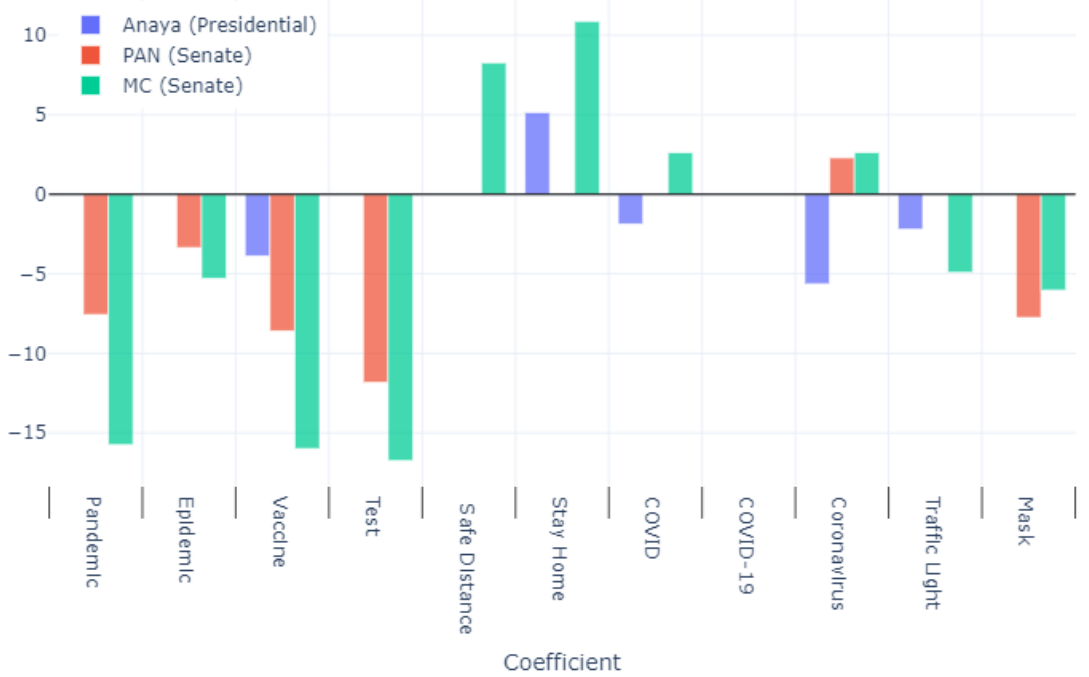

Note: Authors' estimates. Each bar represents a coefficient from the OLS regression for Google Searches of COVID-19 related words and electoral results at the state level. The Index is built using principal component analysis of all google searches. Only statistical significant coefficients are shown. 


\subsection{Awareness, Political Affiliation \& Mobility Change}

The next step is to show that people's mobility is affected by discourse-driven awareness about social distancing measures and other pandemic-related topics. On the one hand, Figure 17 shows that people are more keen to look for COVID related words when they watch the president's daily reports and its czar. On the other hand, states where the president or its party did not have a majority tend to look less for COVID related words in Figure 18.

Furthermore, using both awareness and political affiliation, we devised an alternative endogeneity test. In this strategy, we presuppose that Google Searches are endogenous since they respond to press conferences, and those, may respond to mobility (same argument as in Subsection 5.1). Hence, we test whether Google Searches also respond to new daily global COVID-19 cases and political affiliation. Since global cases and political affiliation are exogenous to the system in Subsection 5.1 , then these variable may work well as instrumental variables. Column (1) in Table 1 presents the relationship between each of these variables and their interaction with Google Searches after controlling for daily COVID cases and fatalities in Mexico, state, month and day of the week fixed effects. All variables are statistically significant at more than 5\% significance. Taking the residuals from this regression, we tested whether the residuals are in turn related to mobility. The hypothesis is that if mobility is not related to Google Searches, then Google Searches are exogenous. Our test revealed that mobility changes at the usual $5 \%$ level, and we thus conclude that Google Searches are exogenous.

Having this evidence and arguments, in Table 2 we show that both political affiliation and awareness are associated to mobility changes. Specifically, we find that more google searches reduce mobility while political affiliation has mixed effects. These mixed effects of politics could be due to mixed messaging of the president and its COVID-19 czar. 
Table 1: Alternative endogeneity test

\begin{tabular}{lcc}
\hline & $\begin{array}{c}\text { Google Searches index } \\
(1)\end{array}$ & $\begin{array}{c}\text { Residuals from (1) } \\
(2)\end{array}$ \\
\hline Daily global COVID-19 cases & $-0.00005^{* *}$ & \\
Votes AMLO \% & $(0.00000)$ & \\
& $0.02772^{*}$ & \\
Votes MORENA \% & $(0.01092)$ & \\
& $0.05346^{* *}$ & \\
Global COVID-19 cases $\times$ Votes AMLO & $(0.01170)$ & \\
& $-0.00000^{* *}$ & \\
Global COVID-19 cases $\times$ Votes MORENA & $(0.00000)$ & \\
& $-0.00000^{* *}$ & -0.00931 \\
Mobility Change index & $(0.00000)$ & $(0.00492)$ \\
& & -0.00278 \\
Constant & $-53.76764^{* *}$ & $(0.39888)$ \\
& $(0.47446)$ & Yes \\
\hline Controls: & & Yes \\
COVID-19 positive cases & Yes & Yes \\
COVID-19 negative cases & Yes & Yes \\
COVID-19 death cases & Yes & Yes \\
State FE & Yes & Yes \\
Month FE & Yes & 235,591 \\
Day FE & Yes & 0.00002 \\
Observations & 235,591 & -0.00018 \\
$R^{2}$ & 0.37288 & \\
Adjusted $R^{2}$ & 0.373 & \\
\hline Colyn $(1)$ has & & \\
\hline
\end{tabular}

Column (1) has robust standard errors in parentheses.

Column (2) has bootstraped standard errors in parenthesis with 1,000 repetitions. ** $\mathrm{p}<0.01, * \mathrm{p}<0.05$ 
Table 2: Awareness \& Political Affiliation on Mobility

\begin{tabular}{lc}
\hline & $\begin{array}{c}\text { Mobility Change } \\
(1)\end{array}$ \\
\hline Google Searches index & $-0.00187^{*}$ \\
& $(0.00084)$ \\
Votes AMLO \% & $0.01333^{* *}$ \\
& $(0.00286)$ \\
& \\
Votes MORENA \% & $-0.01920^{* *}$ \\
& $(0.00327)$ \\
Constant & $-4.19357^{* *}$ \\
& $(0.77348)$ \\
& \\
& \\
\hline Controls: & Yes \\
COVID-19 positive cases & Yes \\
COVID-19 negative cases & Yes \\
COVID-19 death cases & Yes \\
State FE & Yes \\
Month FE & Yes \\
Day FE & Yes \\
H1N1 FE & Yes \\
Census FE & 235,591 \\
\hline Observations & 0.02908 \\
$\mathrm{R}^{2}$ & 0.02883 \\
Adjusted R ${ }^{2}$ & \\
\hline Robust stan & \\
\hline
\end{tabular}

Robust standard errors in parentheses.

${ }^{* *} \mathrm{p}<0.01,{ }^{*} \mathrm{p}<0.05$ 


\section{Conclusions}

In the face of risk assessment and crisis management, preparedness and effective communication from top government officials and health experts can steer the public's response and mitigate the adverse effects of an outbreak.

We analyzed the use of relevant prevention-related keywords mentioned during President's AMLO and HLG press briefings, including the following: epidemic, pandemic, safe distance, stay at home, vaccines, and test. We found that even though both officials conveyed messages encouraging social distancing, the prevalence of those showed a declining trend over time. The timing and word choice are strikingly different, suggesting that there is no concerted communication strategy between these two levels of government.

Our findings show that when AMLO's discourse is positive, mobility tends to decrease compared to baseline. Conversely, when HLG is positive in his COVID-19

conference, mobility increases relative to baseline. Across the distribution of mobility changes, those in the inter-quantile range are more responsive to the discourse. However, the predicted effect of discourse on changes in mobility is small. The association between mobility and AMLO's discourse is not significant.

Conversely, HLG's topics do influence mobility. Whenever HLG's discourse's main issue is mobility, a decrease of 4-6pp in mobility is observed. However, the topic measures in HLG's discourse predicts between 2-8pp increase in mobility in the inter-quantile range of the mobility distribution, with the most considerable effect on the 25th percentile. To address a potential concern of reverse causality, between past mobility patterns and discourse, we use a SUR model to test this hypothesis. Results from that model show compelling evidence on how HLG's discourse in $t$ does not react to mobility patterns in $t-1$, but mobility patterns in $t$ do react to discourse in $t-1$. We also discuss the mechanisms driving these results: 1) people who see the daily morning reports or the COVID reports may be more aware of the current situation due to the latest information presented every day, and 2) political affiliation with AMLO and the Morena party is associated with more considerable reductions 
in mobility during the pandemic.

In sum, our results suggest that mobility can be affected through discourse, but this association is mediated through awareness of COVID-related topics and individuals' political affiliation. Possibly because the message across the top officials analyzed is mixed, the effects are not large. It remains untested whether a concerted message would effectively increase compliance with social distancing. However, we argue that the small magnitude of the effects is not at odds with relevant economic/epidemiological impact. Even slight changes in mobility can set in motion a series of events that can reduce the spread of COVID and ease the burden on the health system, which takes more relevance when considering that health messaging is virtually cost-less as it is incorporated into daily press conferences. 


\section{References}

Aburto, N. J., Pevzner, E., Lopez-Ridaura, R., Rojas, R., Lopez-Gatell, H., Lazcano, E., Hernandez-Avila, M. and Harrington, T. A.: 2010, Knowledge and adoption of community mitigation efforts in mexico during the 2009 h1n1 pandemic, American journal of preventive medicine 39(5), 395-402.

Adolph, C., Amano, K., Bang-Jensen, B., Fullman, N. and Wilkerson, J.: 2020, Pandemic politics: Timing state-level social distancing responses to covid-19, medRxiv

Agüero, J. M. and Beleche, T.: 2017, Health shocks and their long-lasting impact on health behaviors: Evidence from the 2009 h1n1 pandemic in mexico, Journal of health economics 54, 40-55.

Aguilar-Gomez, S.: 2020, Adaptation and mitigation of pollution: evidence from air quality warnings. Manuscript.

Ajzenman, N., Cavalcanti, T. and Da Mata, D.: 2020, More than words: Leaders' speech and risky behavior during a pandemic, Available at SSRN 3582908 .

Allcott, H., Boxell, L., Conway, J., Gentzkow, M., Thaler, M. and Yang, D. Y.: 2020, Polarization and public health: Partisan differences in social distancing during the coronavirus pandemic, NBER Working Paper (w26946).

Baekkeskov, E.: 2016, Same threat, different responses: experts steering politicians and stakeholders in 2009 h1n1 vaccination policy-making, Public Administration $\mathbf{9 4}(2), 299-315$.

Barbieri, P. and Bonini, B.: 2020, Populism and political (mis-) belief effect on individual adherence to lockdown during the covid-19 pandemic in italy, Available at SSRN 3640324.

Barrios, J. M. and Hochberg, Y.: 2020, Risk perception through the lens of politics in the time of the covid-19 pandemic, Technical report, National Bureau of Economic Research. 
Bento, A. I., Nguyen, T., Wing, C., Lozano-Rojas, F., Ahn, Y.-Y. and Simon, K.: 2020, Evidence from internet search data shows information-seeking responses to news of local covid-19 cases, Proceedings of the National Academy of Sciences $\mathbf{1 1 7}(21), 11220-11222$.

Blei, D. M., Ng, A. Y. and Jordan, M. I.: 2002, Latent Dirichlet allocation.

Blei, D. M., Ng, A. Y. and Jordan, M. I.: 2003, Latent Dirichlet allocation, Journal of Machine Learning Research 3(4-5), 993-1022.

Brown, C. S., Ravallion, M. and Van De Walle, D.: 2020, Can the world's poor protect themselves from the new coronavirus?, Technical report, National Bureau of Economic Research.

Bursztyn, L., Rao, A., Roth, C. and Yanagizawa-Drott, D.: 2020, Misinformation during a pandemic, University of Chicago, Becker Friedman Institute for Economics Working Paper (2020-44).

Daverio Occhini, F. N., Montoya-Aguirre, M. and Woo-Mora, L. G.: 2020, Moral force: Leaders' actions and social distancing, Available at SSRN 3678980.

Deslatte, A.: 2020, To shop or shelter? issue framing effects and social-distancing preferences in the covid-19 pandemic, Journal of Behavioral Public Administration $3(1)$.

Fancourt, D., Steptoe, A. and Wright, L.: 2020, The cummings effect: politics, trust, and behaviours during the covid-19 pandemic, The Lancet 396(10249), 464-465.

Fraser, M. R.: 2020, Leading in the covid-19 crisis: Challenges and solutions for state health leaders, Journal of Public Health Management and Practice 26(4), 380-383.

Gallagher, K. M. and Updegraff, J. A.: 2012, Health message framing effects on attitudes, intentions, and behavior: a meta-analytic review, Annals of behavioral medicine 43(1), 101-116.

Gencoglu, O.: 2020, Large-scale, language-agnostic discourse classification of tweets during covid-19, arXiv preprint arXiv:2008.00461. 
Google: 2020, "google covid-19 community mobility reports", Technical report. "Accessed: August 31, 2020".

Green, J., Edgerton, J., Naftel, D., Shoub, K. and Cranmer, S. J.: 2020, Elusive consensus: Polarization in elite communication on the covid-19 pandemic, Science advances 6(28), eabc2717.

Guest, J. L., Del Rio, C. and Sanchez, T.: 2020, The three steps needed to end the covid-19 pandemic: bold public health leadership, rapid innovations, and courageous political will, JMIR Public health and surveillance 6(2), e19043.

Guttman, N. and Salmon, C. T.: 2004, Guilt, fear, stigma and knowledge gaps: ethical issues in public health communication interventions, Bioethics 18(6), 531552.

Hatem, A. and Young, E.: n.d., Beyond partisanship? electoral competitiveness and us governors' policy responses to the covid-19 pandemic.

Jockers, M. M.: 2020, Package 'syuzhet': Extracts Sentiment and Sentiment-Derived Plot Arcs from Text, Technical report.

URL: https://github.com/mjockers/syuzhet

Kirby, D. B., Laris, B. and Rolleri, L. A.: 2007, Sex and hiv education programs: their impact on sexual behaviors of young people throughout the world, Journal of adolescent Health 40(3), 206-217.

Kite, J., Grunseit, A., Bohn-Goldbaum, E., Bellew, B., Carroll, T. and Bauman, A.: 2018, A systematic search and review of adult-targeted overweight and obesity prevention mass media campaigns and their evaluation: 2000-2017, Journal of Health Communication 23(2), 207-232.

Koenker, R. and Bassett Jr, G.: 1978, Regression quantiles, Econometrica: journal of the Econometric Society pp. 33-50.

Koenker, R. and Hallock, K. F.: 2001, Quantile regression, Journal of economic perspectives $\mathbf{1 5}(4), 143-156$. 
MacMillen, A.: 2020, Divergent partisan compliance with shelter-in-place orders during the covid-19 pandemic.

Michie, S., West, R., Amlôt, R. and Rubin, J.: 2020, Slowing down the covid-19 outbreak: changing behaviour by understanding it, BMJ .

Mohammad, S. M. and Turney, P. D.: 2013, Crowdsourcing a word-emotion association lexicon, Computational Intelligence 29(3), 436-465.

Monroy-Gómez-Franco, L.: 2020, ¿ quién puede trabajar desde casa? evidencia desde méxico. "Documento de trabajo, No. 06/2020".

Neidell, M.: 2010, Air quality warnings and outdoor activities: evidence from southern california using a regression discontinuity design, Journal of Epidemiology $\&$ Community Health 64(10), 921-926.

Organization, W. H. et al.: 2020, Novel coronavirus (2019-ncov): situation report, 3.

Syed, S. and Spruit, M.: 2017, Full-Text or abstract? Examining topic coherence scores using latent dirichlet allocation, Proceedings - 2017 International Conference on Data Science and Advanced Analytics, DSAA 2017, Vol. 2018-January, pp. 165174.

Taboga, M.: 2017, "Hierarchical Bayesian models", Lectures on probability theory and mathematical statistics, third edition edn.

URL: $\quad$ https://www.statlect.com/fundamentals-of-statistics/HierarchicalBayesian-models.

Tversky, A. and Kahneman, D.: 1974, Judgment under uncertainty: Heuristics and biases, science 185(4157), 1124-1131.

Wozniak, A. et al.: 2020, Disparities and mitigation behavior during covid-19, Federal Reserve Bank of Minneapolis .

Wright, A. L., Sonin, K., Driscoll, J. and Wilson, J.: 2020, Poverty and economic 
dislocation reduce compliance with covid-19 shelter-in-place protocols, University of Chicago, Becker Friedman Institute for Economics Working Paper (2020-40).

Yi, C. and Huang, J.: 2017, Semismooth newton coordinate descent algorithm for elastic-net penalized huber loss regression and quantile regression, Journal of Computational and Graphical Statistics 26(3), 547-557.

\section{Appendices}

\section{A Figures}

Figure A.1: Daily positivity rate in Mexico

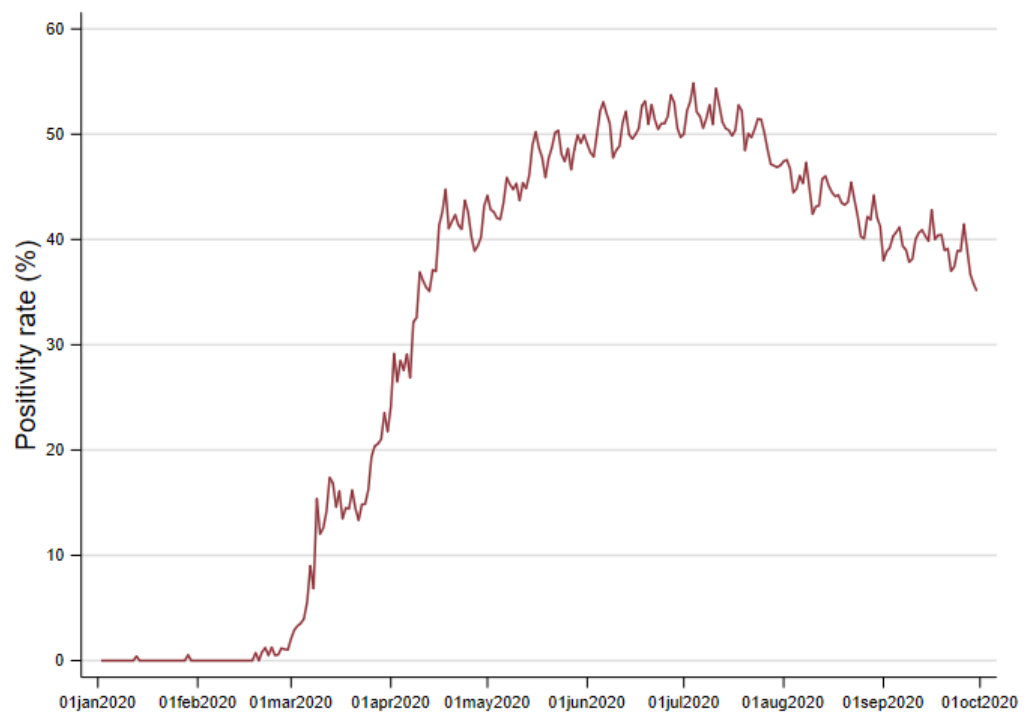

Note: Authors' estimates using data from the General Directorate of Epidemiology from January to September, 2020. The Figure shows daily positivity rate, which is defined as the percentage of positive cases with respect to the sum of positive and negative cases. 
Figure A.2: Word cloud - COVID press conference

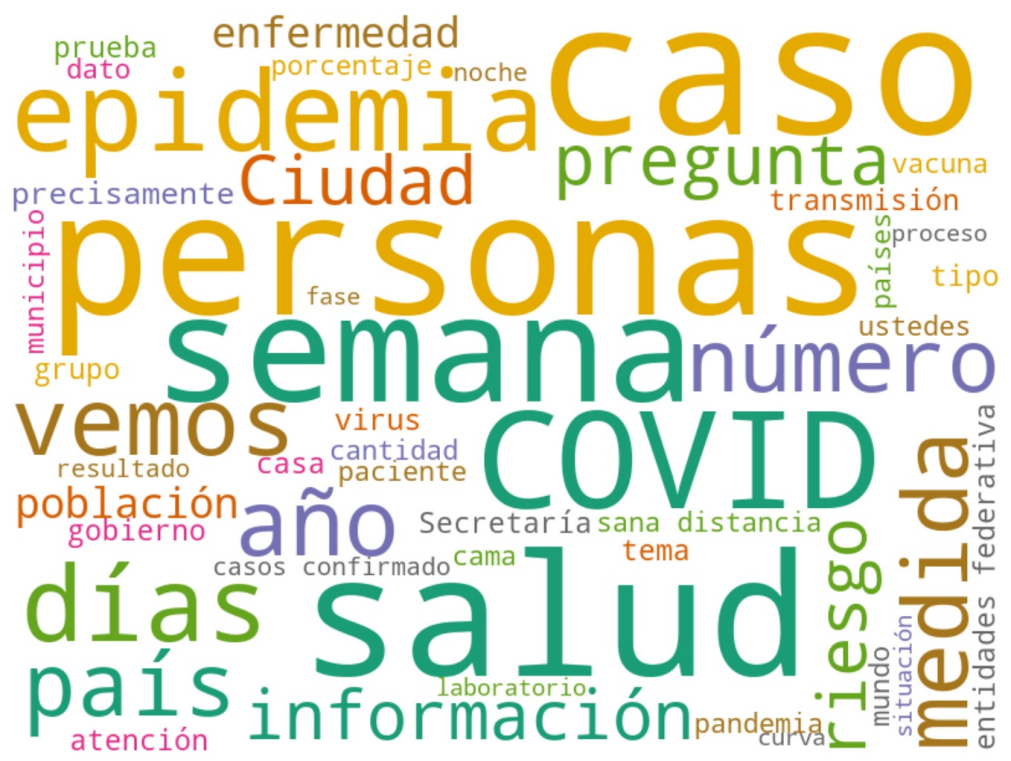

Note: Figure shows the translated version of the wordcloud generated using all the COVID-19 press conferences held by Hugo Lopez-Gatell, the coronavirus czar of Mexico. 
Figure A.3: Word cloud - Daily press conference

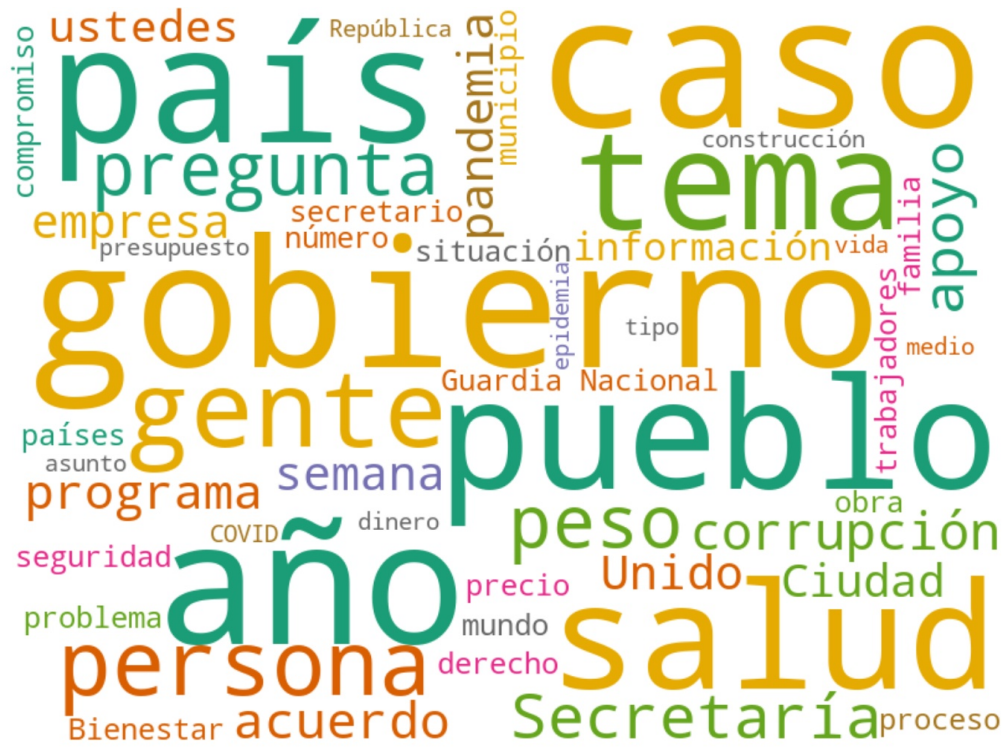

Note: Figure shows the translated version of the wordcloud generated using all the daily press conferences held by AMLO, the president of Mexico. 
Figure A.4: Winners in the 2018 Federal Elections

(a) Presidential election

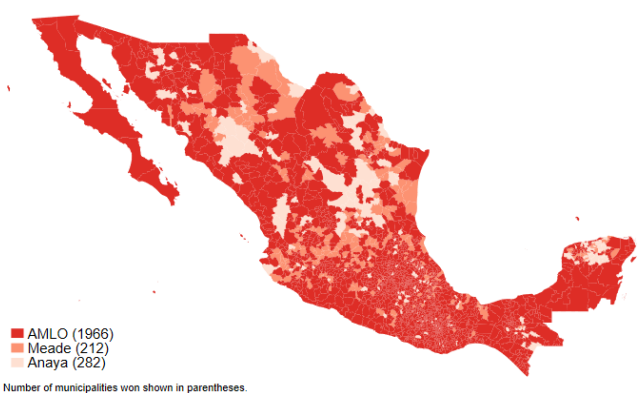

(b) Senate elections

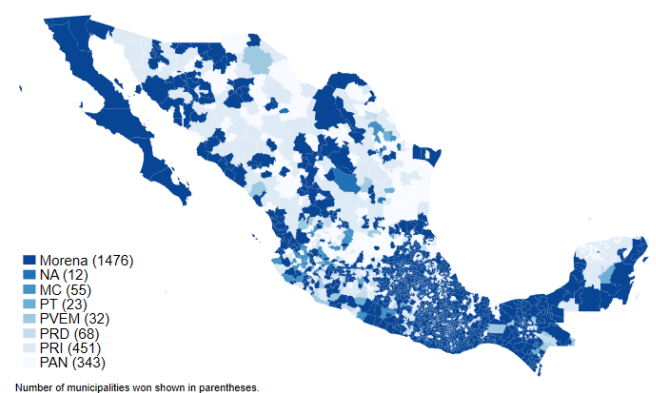

(c) Chamber of Deputies

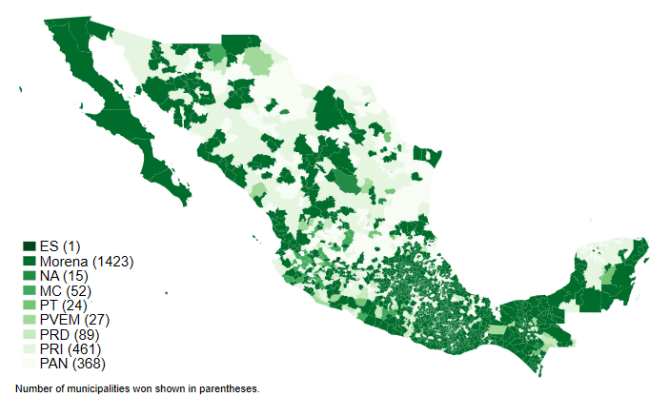

Notes: Authors' estimates using National Electoral Institute (INE) data from the 2018 Federal Elections. (a) presents the presidential candidate who received the most votes; (b), the party of the senator who received the most votes, and (c) the party whose deputy candidates received the most votes. 
Figure A.5: Influenza and pneumonia death cases

(a) Death cases and the H1N1 peak

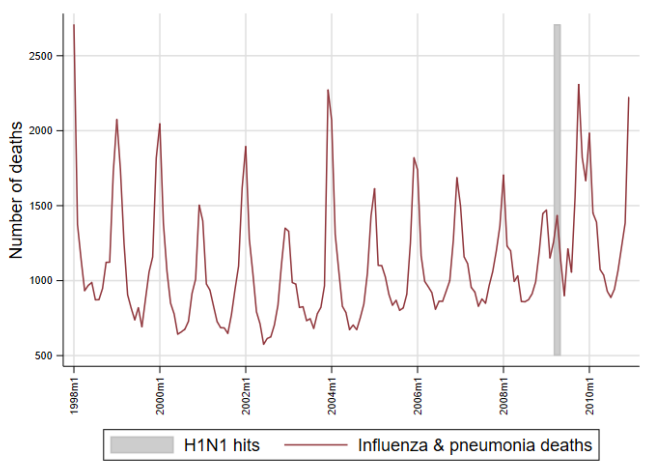

(b) Accumulated excess death cases, 03/2009-12/2010

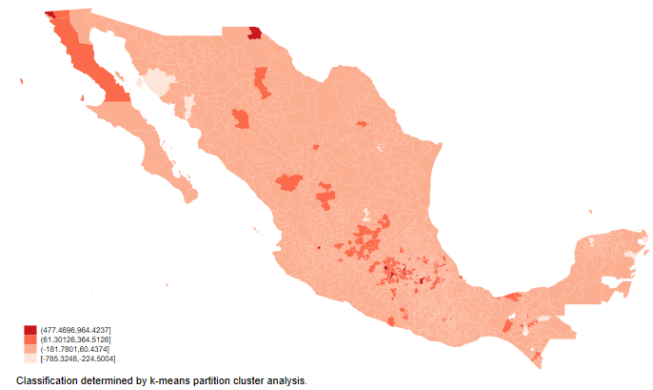

Notes: Authors' estimates using data from the National Health Information System from 1998 to 2010. (a) shows the time series of influenza and pneumonia monthly death cases. (b) shows the distribution of influenza and pneumonia excess death cases between March, 2009 and December, 2010 in the territory. Excess death cases were estimated using a prediction model for the pre-H1N1 pandemic period. The prediction model controlled for municipality fixed effects, municipality-specific time trends and state-specific month fixed effects. This model was used to predict flu and pneumonia deaths in 2009 and 2010. Excess deaths are thus the difference between observed deaths and the predicted deaths. 
Figure A.6: Evolution of keywords in the press conferences

\section{Epidemic vs. Pandemic}

(a) AMLO's

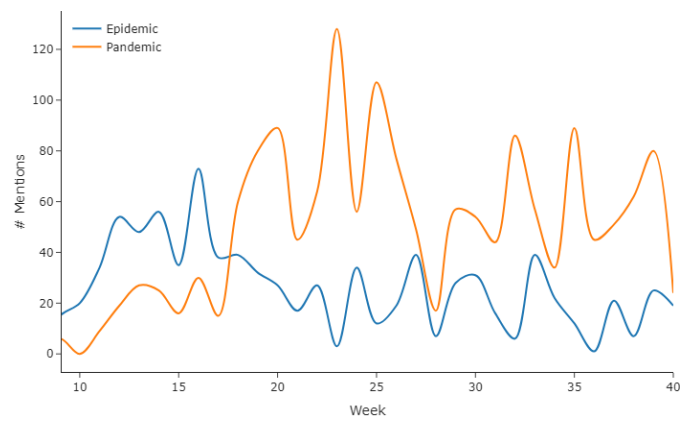

II. Scientific aspect vs. Control (b) COVID-19

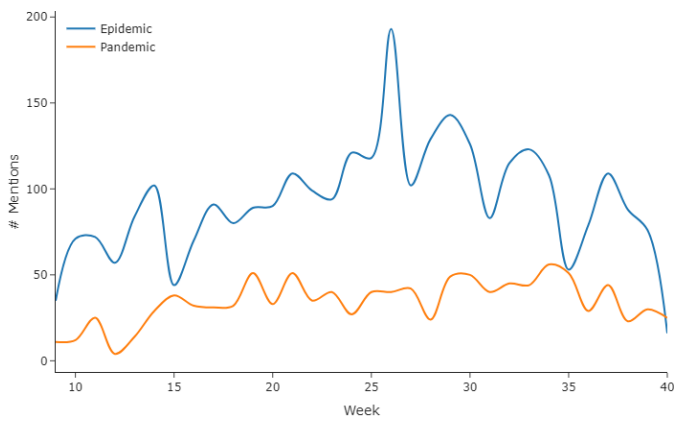

(d) COVID-19


Authors' estimates using data from the stenographic versions of the COVID-19/López Gatell's press conference and AMLO's daily press conference. Each graph presents the evolution of weekly mentions of two keywords over the period of analysis: March 1, 2020 to September 30, 2020. The top, Panel I, presents mentions of "Epidemic" (in blue) and "Pandemic" (in yellow). The bottom, Panel II, shows mentions of "Scientific aspect" (in blue) and "Control" (in yellow). 


\section{B Tables}

Table B.1: Topic modelling: definitions and keywords

\begin{tabular}{|c|c|c|c|}
\hline Conference & Topic & Example Phrases & Top 10 words \\
\hline \multirow[t]{5}{*}{ COVID-19 } & Measures & $\begin{array}{l}\text { Let's all take care of ourselves, let's take care of ourselves } \\
\text { in the community,because in the community } \\
\text { is where the epidemics stop with basic public } \\
\text { health measures, hand washing, sneezing etiquette, not going } \\
\text { out on the street if you are sick }\end{array}$ & $\begin{array}{l}\text { virus, stage, person, } \\
\text { measurements, surveillance, } \\
\text { coronavirus, test, phase, } \\
\text { countries, contact }\end{array}$ \\
\hline & Vaccines & $\begin{array}{l}\text { WHO itself has said that it is too early to say } \\
\text { whether or not it is the vaccine that the whole } \\
\text { planet is waiting for due to the repercussions, } \\
\text { for the time that the studies have to be done }\end{array}$ & $\begin{array}{l}\text { diseases, system, products, } \\
\text { vaccines, virus, life, mortality, } \\
\text { group, countries, strategy }\end{array}$ \\
\hline & Maternity & $\begin{array}{l}\text { I give the example of obstetric care, pregnant } \\
\text { women from Social Security who have gone } \\
\text { to private hospitals and there have been deliveries, } \\
\text { cesarean sections, even other types of emergency care }\end{array}$ & $\begin{array}{l}\text { women, services, pregnancy, } \\
\text { blood, theme, center, adolescents, } \\
\text { woman, violence, entities }\end{array}$ \\
\hline & Information & $\begin{array}{l}\text { We can also see in this graph the percentage of positivity, } \\
\text { that by week } 31 \text { is already } 47 \text { percent, we are starting below } \\
50 \text { percent, having reached this percentage more or less up to } \\
53 \text { percent in previous weeks }\end{array}$ & $\begin{array}{c}\text { trend, entities, color, } \\
\text { deaths, decrease, beds, } \\
\text { increase, tests, percentage, } \\
\text { availability }\end{array}$ \\
\hline & Mobility & $\begin{array}{c}\text { Because mitigation measures imply restricting the } \\
\text { mobility of people and that leads to the massive } \\
\text { suspension of social activities }\end{array}$ & $\begin{array}{l}\text { distance, virus, hospitals, } \\
\text { patients, beds, measures, } \\
\text { person, mobility, deaths, } \\
\text { quantity }\end{array}$ \\
\hline \multirow[t]{4}{*}{ AMLO's } & Economy & $\begin{array}{l}\text { It is considered that Calderon gave a subsidy to the } \\
\text { consumption of gasoline more than one billion pesos, } \\
\text { which means one billion pesos, } \\
\text { one million million pesos. }\end{array}$ & $\begin{array}{l}\text { pesos, case, people, } \\
\text { companies, issue, price, } \\
\text { money, interlocutor, } \\
\text { agreement, water }\end{array}$ \\
\hline & COVID & $\begin{array}{c}\text { A scientist of ours said something in a meeting that } \\
\text { I transmit, that these epidemics are } \\
\text { cured more at home }\end{array}$ & $\begin{array}{l}\text { health, cases, case, hospitals, } \\
\text { doctor, measures, } \\
\text { countries, disease, } \\
\text { theme, epidemic }\end{array}$ \\
\hline & Security & $\begin{array}{c}\text { There has been a decrease in crime } \\
\text { incidence in the five states where we } \\
\text { hold security meetings }\end{array}$ & $\begin{array}{l}\text { security, case, people, } \\
\text { support, secretary, } \\
\text { elements, theme, workers, } \\
\text { companies, credits }\end{array}$ \\
\hline & Public Policy & $\begin{array}{l}\text { The wealth of this region with the skills of the local workforce } \\
\text { in the } 10 \text { development towns that will be created in the area and } \\
\text { that, with the participation of the private and social sectors, } \\
\text { will allow us to generate the jobs they demand the } \\
\text { inhabitants of the Isthmus of Tehuantepec }\end{array}$ & $\begin{array}{l}\text { program, town, governor, } \\
\text { support, women, youth, } \\
\text { development, life, towns, } \\
\text { water }\end{array}$ \\
\hline
\end{tabular}


Table B.2: Seemingly Unrelated Regression: COVID-19, mobility and messaging

\begin{tabular}{|c|c|c|c|c|c|c|}
\hline & \multirow[b]{2}{*}{  } & \multirow[b]{2}{*}{$\begin{array}{c}\text { Fatalities }_{t} \\
(2)\end{array}$} & \multirow[b]{2}{*}{$\begin{array}{c}\text { Mobility } \Delta_{t} \\
\text { (3) }\end{array}$} & \multicolumn{3}{|c|}{ Discourse topics: } \\
\hline & & & & $\begin{array}{c}\text { HLG: Mobility } t \\
\text { (4) }\end{array}$ & $\begin{array}{c}\text { HLG: } \text { Measures }_{t} \\
(5)\end{array}$ & $\begin{array}{c}\text { AMLO: } \text { COVID }_{t} \\
(6)\end{array}$ \\
\hline \multirow[t]{2}{*}{ Mobility $\Delta_{t-1}$} & $-3,236.83899^{* * *}$ & -151.36273 & $0.40420 * * *$ & -1.03361 & 0.59384 & $2.10070 * * *$ \\
\hline & {$[975.54526]$} & {$[120.33341]$} & {$[0.07184]$} & {$[0.77374]$} & {$[0.30614]$} & {$[0.70637]$} \\
\hline \multirow{2}{*}{ Mobility $\Delta_{t-2}$} & $1,254.78823$ & 113.12663 & $0.14040^{* *}$ & -0.43231 & 0.11869 & $-3.90475^{* * *}$ \\
\hline & [876.54213] & [108.07798] & {$[0.06595]$} & [0.81753] & [0.32339] & {$[0.69101]$} \\
\hline \multirow[t]{2}{*}{ Mobility $\Delta_{t-3}$} & 467.51592 & -37.54078 & 0.09913 & & & \\
\hline & [687.42032] & {$[85.11094]$} & {$[0.05968]$} & & & \\
\hline \multirow[t]{2}{*}{ Mobility $\Delta_{t-4}$} & 338.26934 & -99.85027 & $0.10932^{* *}$ & & & \\
\hline & [631.12532] & {$[78.09750]$} & {$[0.05435]$} & & & \\
\hline \multirow[t]{2}{*}{ Mobility $\Delta_{t-5}$} & 749.63786 & $180.16000^{* *}$ & -0.00932 & & & \\
\hline & [628.35141] & {$[77.76419]$} & {$[0.04905]$} & & & \\
\hline \multirow[t]{2}{*}{ Mobility $\Delta_{t-6}$} & $-1,401.57389$ & -201.77859 & 0.01476 & & & \\
\hline & {$[1,171.63559]$} & [144.99777] & {$[0.08288]$} & & & \\
\hline \multirow[t]{2}{*}{ Mobility $\Delta_{t-7}$} & $1,171.65592$ & 193.70878 & 0.12038 & & & \\
\hline & {$[1,361.32206]$} & {$[168.46552]$} & {$[0.09501]$} & & & \\
\hline \multirow[t]{2}{*}{ Mobility $\Delta_{t-14}$} & 38.67791 & 88.04451 & 0.07107 & & & \\
\hline & [736.19888] & [91.11043] & {$[0.05242]$} & & & \\
\hline
\end{tabular}

Standard errors in brackets.

$* * * \mathrm{p}<0.01, * * \mathrm{p}<0.05$ 
Table B.2 - Continued from previous page

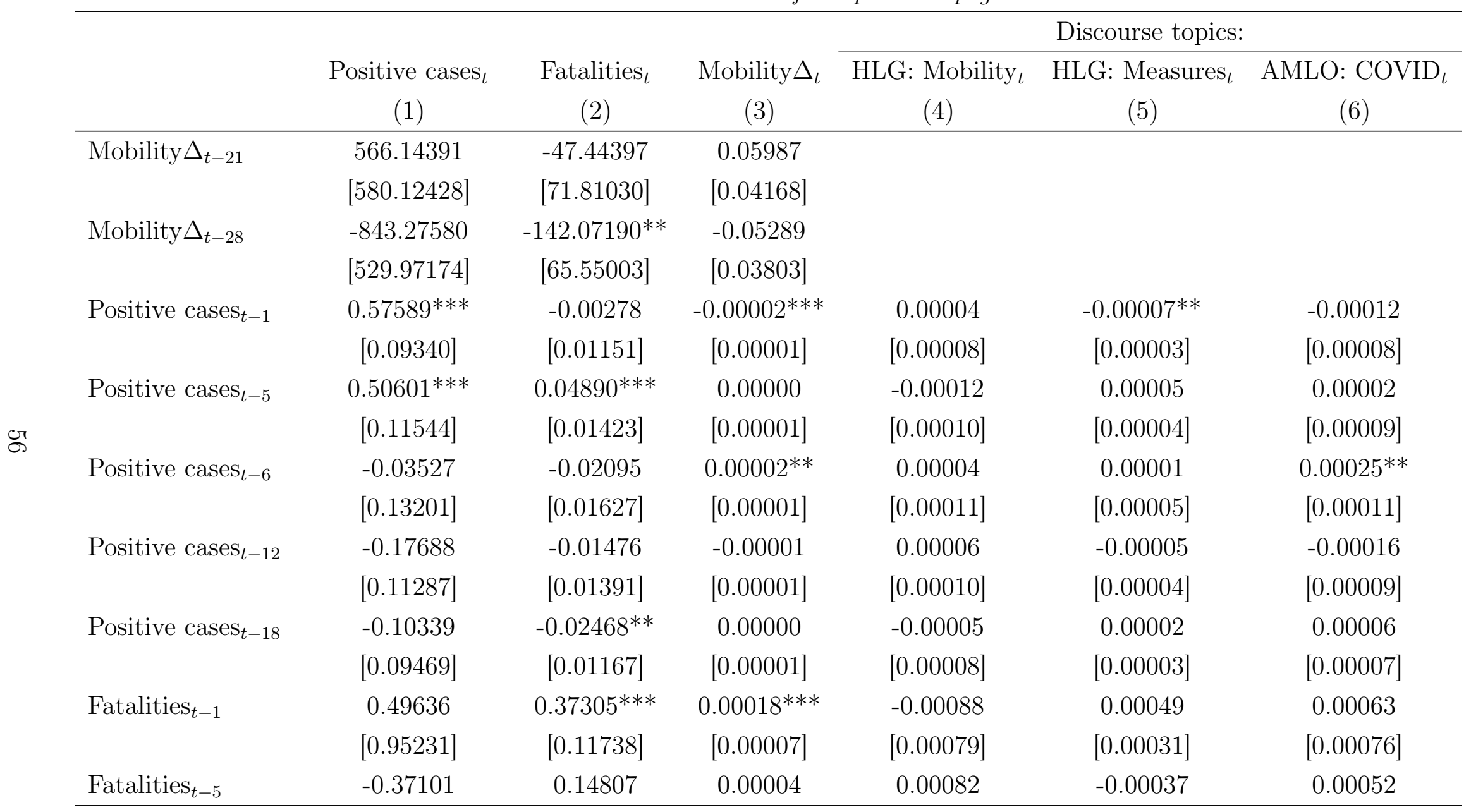

Standard errors in brackets.

*** $\mathrm{p}<0.01, * * \mathrm{p}<0.05$

Table B.2 - Continued on next page 
Table B.2 - Continued from previous page

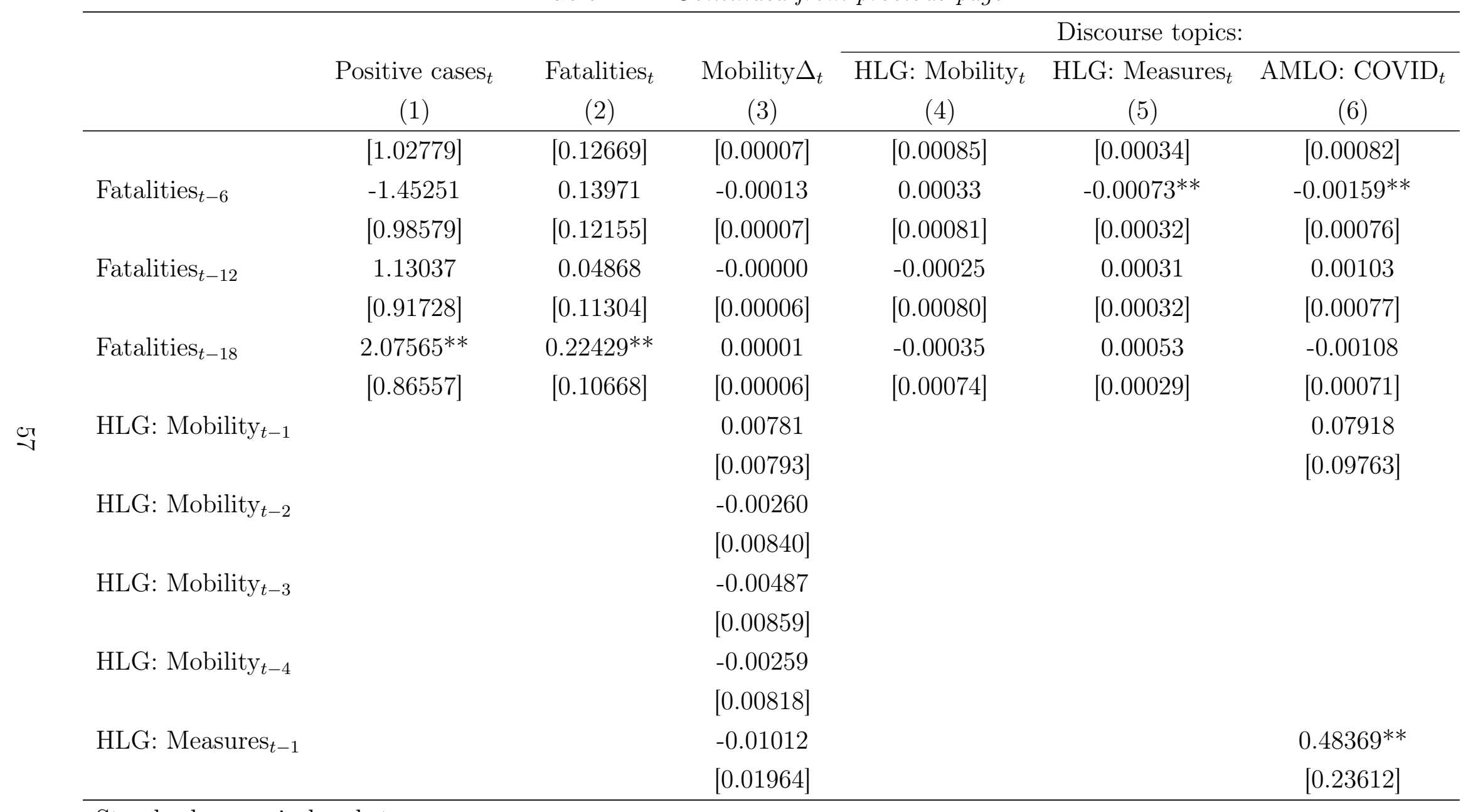

Standard errors in brackets.

$* * * \mathrm{p}<0.01, * * \mathrm{p}<0.05$

Table B.2 - Continued on next page 
Table B.2 - Continued from previous page

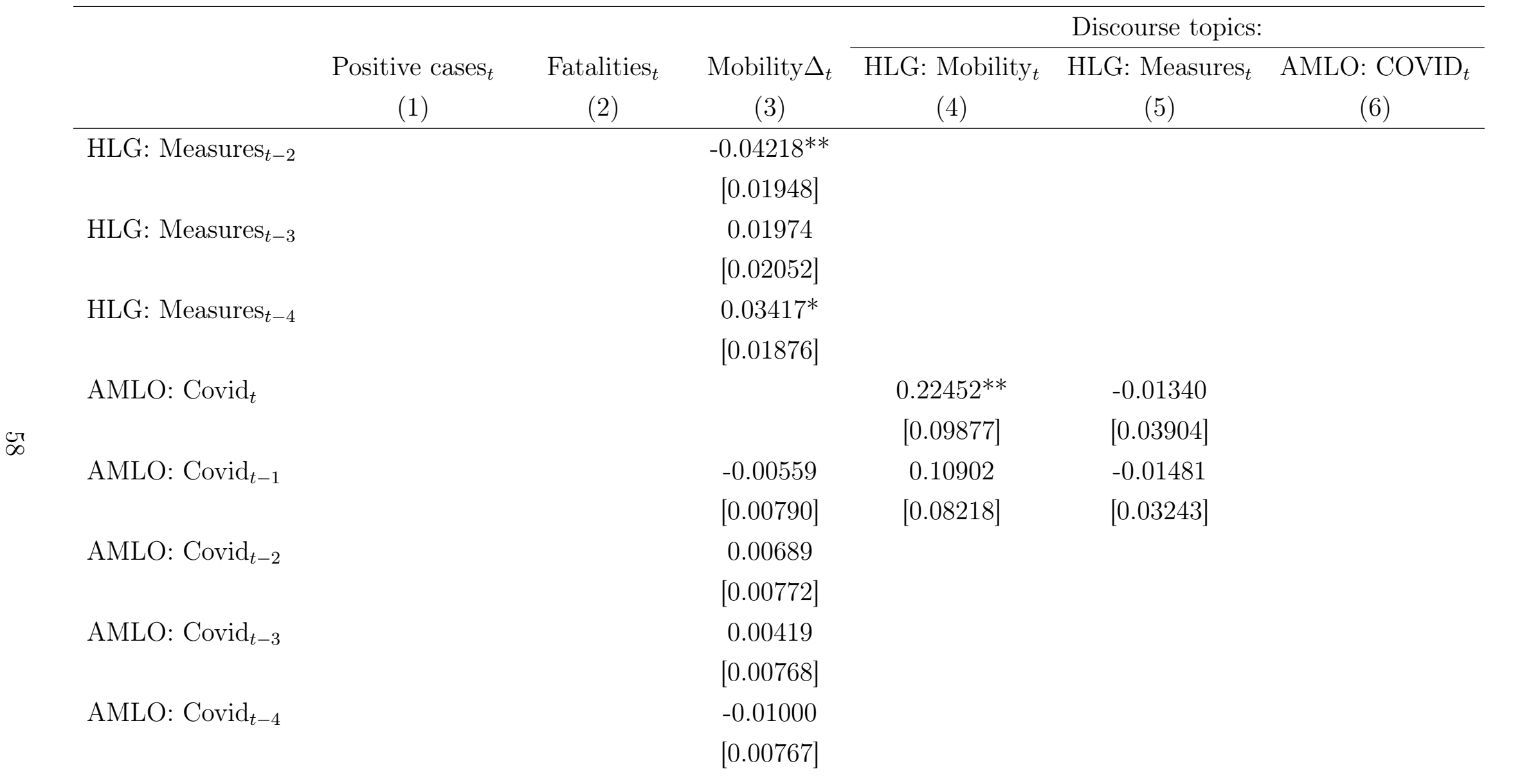

\begin{tabular}{ll}
\hline Standard errors in brackets. & \\
${ }^{* * *} \mathrm{p}<0.01,{ }^{* *} \mathrm{p}<0.05$ & Table B.2 - Continued on next page
\end{tabular}


Table B.2 - Continued from previous page

\begin{tabular}{|c|c|c|c|c|c|c|}
\hline & \multirow[b]{2}{*}{$\begin{array}{c}{\text { Positive } \text { cases }_{t}}^{\text {(1) }}\end{array}$} & \multirow[b]{2}{*}{$\begin{array}{l}\text { Fatalities }_{t} \\
\quad(2)\end{array}$} & \multirow[b]{2}{*}{$\begin{array}{c}\text { Mobility } \Delta_{t} \\
\text { (3) }\end{array}$} & \multicolumn{3}{|c|}{ Discourse topics: } \\
\hline & & & & $\begin{array}{c}\text { HLG: Mobility } t \\
\text { (4) }\end{array}$ & $\begin{array}{c}\text { HLG: } \text { Measures }_{t} \\
(5)\end{array}$ & $\begin{array}{c}\text { AMLO: } \text { COVID }_{t} \\
(6)\end{array}$ \\
\hline Observations & 109 & 109 & 109 & 109 & 109 & 109 \\
\hline$R^{2}$ & 0.99030 & 0.97479 & 0.88513 & 0.46322 & 0.29624 & 0.48688 \\
\hline
\end{tabular}

Table B.3: Correlation matrix of residuals

\begin{tabular}{|c|c|c|c|c|c|c|}
\hline & 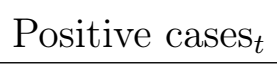 & Fatalities $_{t}$ & Mobility $\Delta_{t}$ & HLG: Mobility & HLG: Measures ${ }_{t}$ & AMLO: COVID $_{t}$ \\
\hline 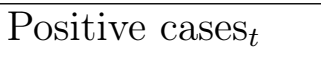 & 1 & & & & & \\
\hline Fatalities $_{t}$ & 0.4872 & 1 & & & & \\
\hline Mobility $\Delta_{t}$ & 0.2876 & 0.1273 & 1 & & & \\
\hline HLG: Mobility $t$ & -0.048 & 0.032 & 0.0631 & 1 & & \\
\hline HLG: Measures $_{t}$ & 0.038 & -0.0828 & 0.0191 & -0.3951 & 1 & \\
\hline AMLO: $\mathrm{COVID}_{t}$ & -0.1303 & -0.0642 & -0.0493 & -0.0224 & 0.0213 & 1 \\
\hline
\end{tabular}

Breusch-Pagan test of independence: $\chi^{2}(15)=58.078, p-$ value $=0.0000$. 
Table B.4: Mechanisms: Regression Results

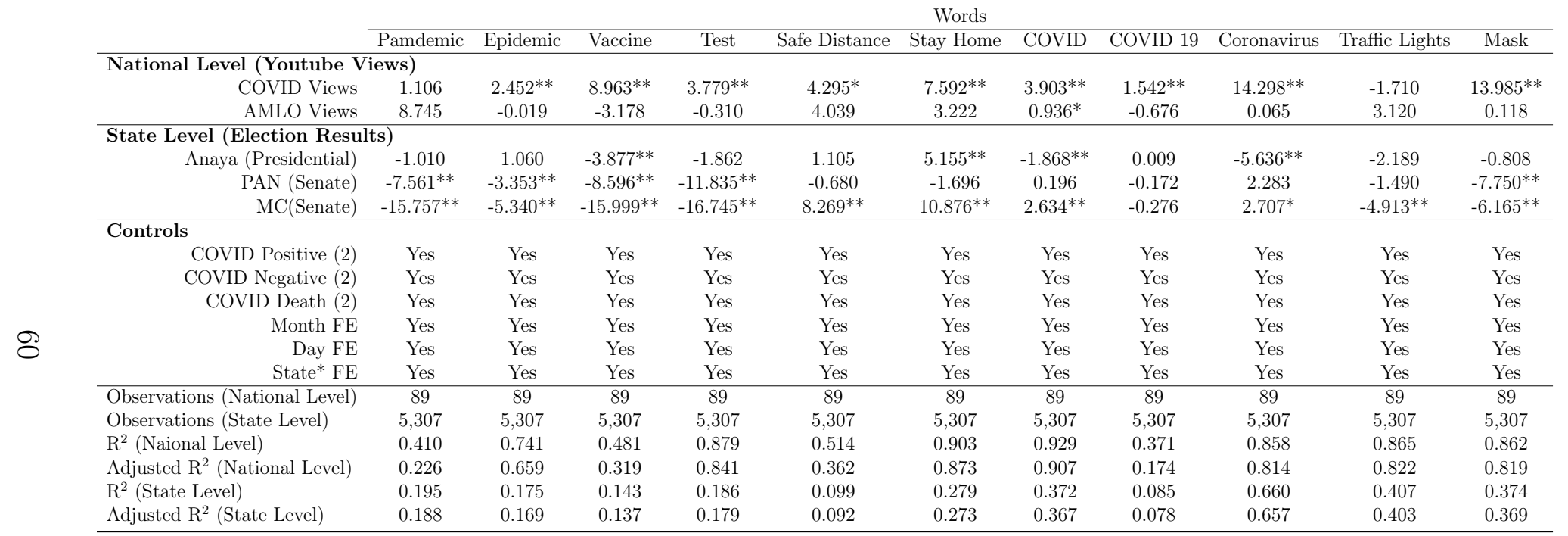

Number of lags are shown in parenthesis. For the State Level regression, AMLO (Presidential) and MORENA (Senate) are taken as base for comparison. The Index is measured using the first principal component of all google searches. This procedure is done once ate the National and once at the State level.

* Only for the State Level regression.

** $\mathrm{p}<0.01, * \mathrm{p}<0.05$ 